\title{
The Emergent Synthetic Brain Concept of Law as Action Type
}

\author{
By \\ Dr Gary Bagnall \\ Newton, MA
}

\begin{abstract}
This paper is a review and restatement of the theory of law in Law as Art (Bagnall, 1996), in light of current scholarship and as prolegomenon to an ethnographic analysis of commensurable legal phenomena. Law is a real physical and symbolic social phenomenon. A compound cluster property. Individual legal works combine to form a distinct social network, or 'nesting', explicable within contemporary Quantum, Complexity, Pattern, System and Network theory. Legal works are conceived within an emergent synthetic human brain concept, a neurological mind mapping of a differentiable domain of coherent, sentient factual data, drawn from experience. This mapping identifies the work as law and enables enactment of the heuristically distinct structure. As an action type, it is a dynamic, variable dramatic enactment in which text and power are dominant indexing criteria. Text constitutes the legal work the way a libretto does an opera, or a script, a play. Law is the enactment of a heuristically distinct structure capable of an infinite set of equal, inchoate enactments. A work is ethnographically individuated as a 'law-candidate', using the identifying hypothetical indexing criteria and differentiated as 'law' by its unique primary and secondary criteria, scraped using the conceptual heuristic. By Quantum analogy, it structurally integrates through audience, observer engagement, where multiple works may share a common provenance and style. Multiple works of common provenance neurologically cohere, integrate and organise as a legal system.
\end{abstract}

\section{Introduction}

Law as Art (Bagnall,1996) presented the 'Law as Compound Action Type Hypothesis' (LCATH) as best explanation of the concept of law. An explanatory heuristic applicable to law transhistorically and culturally, yet making no claim to universal truth. A new legal realist theory owing everything to a contemporary milieu transcending orthodox legal provenance, school and tradition. This current paper has two objectives: (1) to stimulate overdue critical engagement with the thesis and (2) to review and restate it in light of significant recent theoretical scholarship, thereby laying the groundwork for a morphology of LCATH as type. In this restatement, contemporary Anglo-U.S. legal phenomena will be engaged to illustrate how such an innovative legal theory can effectively explain and differentiate legal works, even where the historical heuristics are strikingly similar. The distinguishing criteria of 
the milieu within which LCATH emerged provides a useful introduction to this restatement.

The Enlightenment elevated rationalism, science and individualism. The beaux arts of Batteaux, Smithonian laissez-fair capitalism, Rousseauian 'social contract' of citizens and Benthamite and Austinian legal theories of Sovereign rule all emerged as autonomous, largely incommensurable domains of inquiry. Craft was not art; merely commodity. Psychologically, we live as individual, rational economic self-maximisers, engaging in win/lose commodity transactions. Empathy, altruism, goodness and community the ascribed domain of theology, philosophy and sociology. Obligation to obey the state flowed from an actual contract for protection or was inferred as a hypothetical contract, consented to as preferable to the horrors of a Hobbesian 'state of nature'. This, notwithstanding the data that all states coerce compliance, claiming a territorial monopoly of coercive force. In England the sovereign legal authority was assumed a priori, as was the right to demand fealty and the obligation to obey. In the U.S., a theistic Constitutional Republic claimed sovereign legal authority, enforcing an 18th century set of claimed Divinely granted 'natural human rights'. Rights deemed natural and universal, whether or not formally legally posited. Science was the discovery of the universal structure and function of a fixed mechanical world. This mechanistic, foundational, scientific paradigm provided the foundational epistemological heuristic for all other domains of knowledge aspiring toward objective truth. Such universal, autonomous domains of inquiry generated solipsistic, objective truths from which was deduced all knowledge of reality within that domain. Science, art, law, politics and economics, autonomous in methodology, subject matter and in their own truths. Orthodox Anglo-U.S. legal theory was constructed within this paradigm.

By late the early 20th century, knowledge of reality had become permanently and radically re-conceptualised as a single, interwoven 'web' of belief. The universal became contextual, open texture replaced closed, open societies preferred to closed. The surface of reality (literally) cracked open and revealed a coexisting smallness, magnitude, predictability and randomness. The human role was re-conceptualised as neural architect, constructing a reality from shared reportage of sentient facts. Wittgenstein exposed the open texture of language. Duchamp's gallery installation of a commercial urinal, opened art to craft. Picasso abstracted, then restructured, form, colour and perspective. Music transcended tonality and formal harmony. Jazz syncopated the blues, then embraced world music. In science, Quine's 'one web' of knowledge erased boundaries and encouraged methodological and conceptual commensurability. Physics, chemistry and biology experienced serial, exponential Kuhnian paradigm shifts. Quantum, network, system, pattern and complexity theory was emerged. Analogue was digitalised. Communications became digital, social and virtual. Neurobiology, computer science and AI advanced exponentially. Medical therapeutics embarked upon a new Golden Age and in contemporary materials physics, biocentrism dared to collapse space, time and physical reality within conscious observation.

Anomalously, Anglo-U.S. legal theory, constrained by a powerful professional, political and economic orthodoxy, made modest incremental critical development. Nothing to compare with the seismic shifts elsewhere. Anglo-U.S. legal scholarship persists in resisting change, stubbornly retaining its 18 th -19 th century Enlightenment concepts, epistemology, methodologies and reasoning, within a discarded universal, mechanistic, scientific paradigm. As if the tectonic intellectual, substantive and methodological changes wrought elsewhere, across the entire domain of human knowledge, had either simply never occurred, or were of 
little or no relevance to the autonomous Leviathon of Law's Empire (per Dworkin, 1987).

Developments in legal theory during this period were modest, but not insignificant. The late 1970s to mid 1990s was a period of renewed interest in theory within Anglo-U.S. scholarship. Law and Literature, with a sub genre of Law and Semiotics, illuminated the textual, interpretive aspect (Binder, 2006). Law and Feminism focused attention on the pervasive significance of sex and gender in legal structures and outcomes (Levit, Verchick and Minnow, 2016). Economic Analysis of Law (EAL) extended the methodology of transactional economics to law (Posner, 2014). Critical Legal Studies (CLS), initially countered from a revisionist Marxist perspective, exposed economic inequality and exploitation inherent in that economic system (Unger, 1996, 2015). Emphasising economic relations, power and ideology, it re-presented all law as politics (Douzinas and Perrin, 2011). Naturally, these movements intersected. As law was politics, CLS gradually embraced the critiques of other movements to challenge the status quo. CLS became a platform within which EAL, Law and Literature, Law and Feminism amongst others, could collectively critique legal orthodoxy, joined by revisionist legal realists in the U.S. In retrospect, one can evaluate their impact. CLS is notable for having little residual legacy. It's plea for the economically oppressed heard, listened to then silenced as Marxist theory and economics became largely discredited. Literary, feminist and economic movements gradually asserted independence, leaving New Legal Realists as the residual core of contemporary CLS.

These distinct perspectives are all now well established, insightful legal disciplines in their own right. Comparative literary study, hermeneutics and semiotics continue to make an important contribution to Anglo-U.S. legal scholarship, given the focus on the written text. However, the two legal orthodoxies; English 'formalism' (exemplified by Hart 1961 and Raz 1980) and U.S. 'substantive instrumentalism' (by Posner 1990, 1996, augmented by Dworkin 1987), do not restrict the idea of law to text. Common indexing criteria include rules, norms, rights, principles and policies along with concepts of power, sanction, justice, authority, sovereignty, adjudication, restitution, equity and stare decisis (precedent). Law as more than a differentiable class of text, ontologically. Formalism and substantive instrumentalism both originate within the 18th and 19th century paradigm, in which law, politics, science, economics and art were conceived as rational, autonomous domains of knowledge. The English system emphasises form over content as sufficient criteria of legality. The U.S., content over form, legality being in proportion to instrumental utility in furthering that content. The professional classes of both jurisdictions continue to dismiss legal theory as worthwhile inquiry. The concept of law being either, an uncontested systemic concept or if contested, exhaustively analysed without offering sufficient explanatory insight to merit future investigation.

In legal theory, the Oxford Logical Positivists laid the foundation for the empirical, open texture of Hart's ground breaking Concept of Law (1961): as the 'union of primary and secondary rules'. The U.S. counterpoint of Raz's emphasis on legal authority (1980) was Dworkin's judicial 'Hercules' (1987), arriving at correct legal answers using flexible principles and policies. Hegelian/Marxist determinism resurfaced in the relativism of CLS and Posner advocated a U.S. pragmatic instrumentalism (1990), simultaneously championing an EAL that applied hypothetical statistical modelling of economic self interest in output, capital and commodities to legal phenomena. A restatement of Medieval Scholastic ideas of 'natural rights, justice and ethics' - resonant with the faith based creation myth of U.S. Constitutional rights-was made by Finnis in England (2011). By the late 20th, early 21st century, U.S. legal scholarship from Leiter (2007) and Tamanaha (2001, 2009, 2012, 2015) sought to effect a 'naturalistic turn', partly 
forward toward embracing scientism, but mostly back to early 20th century legal realism of Holmes and Frank. The orthodox reality of contemporary legal systems was held the correct subject of legal inquiry, the inherent weakness in this position being the lack of any convincing account of law per se, sufficient to enable individuating legal from non-legal systems. Innovative legal theory did emerge, coherent with the prevailing 20th century multidisciplinary zeitgeist, not least Manderson's remarkable artistic reimagining of law as Songs without Music (2000). A work of legal scholarship only possible from a trained concert pianist.

Within the new paradigm of a unified domain of knowledge, Law as Art continues this scholarly intersection between law and the humanities (Sarat, 2009). Yet the nucleus of the concept of legal art work also incorporates ideas from contemporary scientific epistemological realism, theory of art as action type, the concept of compound art work, contemporary brain science and post Quantum, Network, System, Pattern and Complexity theory. It directly refutes the orthodox legal autonomy thesis of both English formalism and U.S. instrumentalism. It strongly rejects Posner's 'futility thesis', from his celebrated Clarendon Inaugural Lectures, with respect to all legal theory.

"...trying to define 'law' is futile, distracting, and illustrative of the impoverishment of traditional legal theory." (Posner, 1996: vii)

For Posner, such theorising is only futile because a convincing universal theory of law is not achievable, not because the analytical objective is itself valueless. In fact, his neotraditionalist, pragmatic view of law shares significant structural similarity with Law as Art, albeit via a very different heuristic (Bagnall, 1996: Ch.6). In associating legal validity with what substantive laws do, not just what they are formally, Posner is coherent with the LCATH for which law is a complex action type, not reducible to a rationally deduced normative proposition. Law is an enactment of a unique structure of unique heuristic.

In the classic comparison of the Anglo-U.S. legal systems, Atiyah and Summers (1987) stress the significance of their distinctive "visions" of Law. A vision of law is

"...a set of inarticulate and perhaps even subconscious beliefs held by the general public...and, to some degree, by politicians, judges, and legal practitioners, as to the nature and function of law-how and by whom it should be made, interpreted, applied, and enforced... ...the views of professional lawyers and judges about the law are bound to be more soundly based and more sophisticated than the views of the general public. So there can never be a complete congruence between the two." (Atiyah and Summers, 1987: 411)

They proceed to add that

"In the daily life of a society, it is not possible to maintain a firm line between evidence of a 'vision' of law and evidence of an explicit theory of the nature or uses of law." (Atiyah and Summers, 1987: 412)

From this perspective, a vision of law is differentiable, but not individuated from a concept. They intersect substantively by degree of common indexing criteria. Furthermore, such a difference is only tenable if the idea of legal concept excludes engagement of law as constitutive and thereby itself a valid conceptual indexing criteria. That engagement is constitutive, is precisely what Law as Art claims. It holds that a brain concept is a personal, neurological vision. So any distinction 
between vision and concept is misleading if not untenable. The concept of law transcends the indexing criteria of the 'insider' orthodoxy within a legal phenomena. It includes all legal experience, of both system 'insiders' and 'outsiders', as crucial to understanding the LCATH. It also describes another key criteria, that all engagement of law is quantitive, qualitative and by varying degree, incomplete. Incomplete, yet to degree constitutive of the concept of law.

It is Atiyah and Summers conclusion that,

“Legal theories must take account of actual legal phenomena..., if they are to have adequate descriptive power. If we find that some legal theories more accurately represent features of some legal systems, and other legal theories better for other systems, the prima-facie conclusion must surely be that the search for universal legal theories about the very nature of law and other legal phenomena is of rather limited utility." (Atiyah and Summers, 1987: 418)

This is correct for legal theories claiming universal truth, but the LCATH is a universally applicable theory of Law, the truth of which is contingent and open. It therefore satisfies their test for an acceptable form of universal legal theory.

“...we do not deny that it may be possible to devise theories at a sufficiently high level of abstraction to accommodate all variations between the differing conceptions of law used in particular legal systems." (Atiyah and Summers, 1987: 417)

The error is in conceiving such a theory as an abstraction from indexing criteria, whereas it is a reverse loop. It is a universally applicable heuristic, not abstracted but extracted from legal experience, revised to include the criteria indexed by its application. Thereby explaining the concept of law within a given socio-legal context. The heuristic is both abstract and plastic. The criteria and pattern produced, detailed and system specific. In contemporary brain science, all knowledge is brain knowledge and all brain knowledge is conceptual. Following Werner (Bagnall, 1996: Ch.2), there can be no 'immaculate perceptions'. All knowledge is therefore neurologically constructed from incommensurable, sentient, theory saturated facts and commensurable truths. All within an existing conceptual systemic web of knowledge. Truth is defined as correspondence with reality-but the criterion or epistemic principle for generating that truth, is coherence with prior accepted systemic truth. As will be argued, the LCATH is an acquired, a priori systemic truth. A synthetic brain concept used heuristically to scrape legal indexing criteria from experience of real social systems of regulation and control, thereby providing open ended critical conceptual revision as best explanation of the legal phenomena.

Given this introductory framework, what then are the differentiating criteria of the compound LCATH and how exactly does it function as a universally applicable theory of law?

\section{Part I: Law and the 'Naturalist turn' of Leiter and Tamanaha}

Law is a distinctive kind of compound action type with unique structure and heuristic. Law as Art (1996) goes further and asserts that law is an artistic action type. Law as the most persuasive, continuous and important artistic form so far produced by human society. This 
proposition is argued for at length throughout, differentiated as the 'Law as Art Hypothesis'. From the Glossary,

"Law as Art Hypothesis - in legal ontology and theory, the hypothesis that law is best explained as a kind of artistically valuable action type." (Bagnall, 1996)

As truth, it is a contingent not universal hypothesis, essential to the best explanation of a valid concept of law, but not ontologically. It is an additional criterion of legal validity. For present purposes, it is sufficient to understand the important function of the metaphorical heuristic of the artistic work type: the operatic music drama. It is the analogical heuristic that best explains the complex structure of legal work, as type. A dramatic enactment of dynamic, artistic activity, each performance being of the same work and of variable cohativity. As a homeostatic cluster property, it is a unified, compound art work in which text and music (power, for legal works) along with all other indexed criteria-are unified though performance or enactment. An enactment within which the audience (widely understood) is importantly constitutive of the very work itself. In simple terms, this is the best explanatory structural metaphor for the phenomenon of a legal work. As the helix is to the genome, the compound art work is to law. Both the helix and operatic music drama are metaphorical heuristics that provide epistemic access to the concepts of genome and law. The argument in Law as Art (1996) simply goes further and holds valid law to be a kind of art work. For present purposes, this artistic ontological and aesthetic criterion of legal validity will be acknowledged, to be exposited elsewhere. It is sufficient here to acknowledge its central metaphorical function.

The LCATH, as legal theory, has three general components: (1) the epistemological; (2) the ontological; and (3) the methodological. How can we know law? What kind of entity is law? How to use the LCATH to get the best explanation of what law is in any given legal system? The first and second are the subject matter of Law as Art (1996). The third, the methodological component, requires a detailed ethnographic, morphological analysis of legal phenomena across a diverse range of current and historic socio-legal phenomena. It will be the subject of a future monograph: The Art of Law. This paper is a prolegomenon to that work. Taking each of the three components in turn.

\section{(1) The epistemological component}

Together, the epistemological and ontological components affirmatively answer the question:

"Are all actual legal systems manifestations of one basic type of of social institution?" (Burge-Hendrix, 2008: Ch.2)

We know law because knowledge of facts and truth provides a degree of epistemic access to objective reality. Truth has both a definitional and criteriological aspect. To briefly recapitulate, truth is defined as knowledge that corresponds with reality. Defined as correspondence, but the criterion applied to determine truthfulness is coherence with prior truths, within a single web of belief. Coherence itself is understood as the best explanation of that reality. Given the definitional/criteriological dimensions of truth, and the measure of best explanation, truths (but not facts) are commensurable, inductive and therefore contingent. A datum is true to the extent that it is the best explanation that corresponds with that reality. If a better explanation is 
preferred then that will be true and the prior explanation discarded, to the extent that it does not cohere with the new best explanation. In sum, there are no universal truths, only fallible, contingent ones. There can be no universally true theory of law (Law as Art, 1996: Ch.2), since conceptual brain knowledge is always a partial, incomplete explanation of reality. As Kövecses describes it, at its simplest any

“...conceptual domain is any coherent organisation of human experience." (2002: 4, quoted in Paterson, 2019: Part II)

How does this apply to the LCATH? Understanding the concept of law flows from shared knowledge of actual legal phenomena. This process of experiential data scraping generates indexing criteria that are legal indentifiers for that particular phenomena and abstracted to constitute the best explanation of the concept of law. All knowledge is conceptual brain knowledge and as such is theory saturated so there are no 'immaculate perceptions'. This means that, epistemologically determining knowledge-indexing legal criteria, involves engaging legal systems or individual laws within a heuristic, conceptual model of law and in reverse, evaluating that model as an explanation. Therefore, the LCATH claims that to know law one engages legal phenomena by applying the LCATH and evaluating the explanatory fit. All theories of law are logical epistemological explanations claiming to be the best contingent explanation. None are universally true, despite the claims made for them.

\section{(2) The ontological component}

This is how we know law, but what kind of entity is it? Qualifying Law as Art, it will be argued that law is a human acquired synthetic brain concept. Not a natural, biologically fixed, inherited concept, but open, revisisible and capable of negation. This has significant implications.

What then differentiates the synthetic LCATH? It is structurally a compound action type. In Law as Art (1996: Ch.7), it is an artistic action type. As action type, it's performative, enacting actions are its tokens, actions arrived at within a unique heuristic. As action type the 'Instance Multiplicity Hypothesis' applies. Simply put, this holds every legal work capable of multiple instances, each being to some degree (of structure and heuristic) an instance of the same work. Consider the crime of theft. The action type of a police officer arresting someone who they witness snatching a pocket book and the act of reading the statute Code within which a written text describes the punishable crime of intending to permanently deprive another of their property, are both instances of the same legal work of criminal theft or larceny. The police officer acting upon seeing what she knows from training, is a crime being committed; the thief taking the pocket book which they know is not theirs and running away; the owner of the pocket book having their pocket book taken without their consent and the act of reading the statute which the reader knows contains criminal laws (works) in that system, (and not works of literary fiction) are all tokens constitutive of the action type of the same legal work of theft. They are all enactments of the same legal work. Not just of the textual or logical normative element, nor the conventions and procedures clustering around the textual artefact. The text is partially and significantly constitutive of the works unique structure and heuristic. Like a script to a play or a libretto to an opera. 
An important ontological question is morphological and only introduced in Law as Art, as it is the subject for a new monograph. It is this: What are the identifiers for a work that is a promising law-candidate, in order to apply the LCATH? In other words, what are the de minimis identifying criteria of legal works extracted from all other possible works of similar structure? All legal knowledge derives from phenomenological experience of actual laws and social networks. Applying the LCATH is a process of scraping indexing criteria from real legal phenomena. Arriving at a priori applicability criteria is also a process of scraping a contingent set of minimal basic facts from our experience of these actual phenomena. This set is continually updated as the LCATH is applied to the sensory data. It is a presumptive hypothesis, the content of which functions solely to efficiently determine applying the metaphorical heuristic of the LCATH. It is structurally non-determinative, purely procedural. To differentiate these applicability criteria from the primary and secondary indexing criteria scraped of legal phenomena, they are best described as the hypothetical indexing criteria for applying the LCATH. They are contingent criteria about lnaw and as such, epistemic inputs not outputs. In Law as Art (Ch.7), these hypothetical criteria, were scraped from personal experience and sensory knowledge of phenomena and their unique originating heuristics, within the AngloU.S. socio-legal systems. There are five:

HIC 1 - Law is a complex reality capable of being engaged abstractly and conceptually (the idea of Law) but also socially and functionally (as a legal system) and semantically (e.g. as 'law', 'loi', or 'recht').

HIC 2 - The conceptual, systematic and semantic senses of law are experiences of a unified, homeostatic entity, rather than elementally heterogenous.

HIC 3 - Law is elementally compound, with a primary textual element, but not reducible to the textual element alone.

HIC 4 - Law is anthropocentric but not ethnocentric.

HIC 5 - Law is about social regulation through the medium of a differentiable class of text.

The reference to homeostatic entity in HIC 2, is the claim that law is ontologically a homeostatic cluster property. It should be noted in passing, that this is a critical scientific and artistic structural quality of the legal work. The ontological component holds law as strongly radical and systemically integrational. It is a non-reductionist ontology that explains all legal systems to which the hypothetical identifiers and LCATH can be applied. It is also non-foundationalist, non-universalist, thereby reinvigorating legal theory as an open, not closed, inquiry.

\section{(3) The methodological component}

The question remains: How to use the LCATH to get the best explanation of what law is, as conceptual type or in a given legal system? This methodological question asks:

"Should legal theorists purposely attempt to develop a single overarching concept of law?" (Burge-Hendrix, 2008: Ch.2) 
What Burge-Hendrix calls the "unitary concept of law" (2008: Ch.2), the principle argument against which, is the possibility of accounting for the diversity of institutional structures and social practices within actual legal systems. This critique only carries weight against a universal legal theory, not the LCATH, which is theoretically of non-universal truth but of universal applicability. As Burge-Hendrix notes, the theoretical ideal of a unitary concept of law has many methodological benefits, as it would

"First,.......allow us to to see and compare the form of the ancient Roman legal system, the sixteenth-century Germans and the modern-day Canadian legal system. Second, a unitary concept...elucidated by a general theory of law would provide...what some consider the most philosophically interesting account of law, namely one which focuses on the persistence of a particular form of human social organization...one which seems common to most all human societies. Finally,...giving legal theorists a common ground upon which they could pursue more detailed debates about law itself." (Burge-Hendrix, 2008: Ch.2)

This is precisely what the LCATH facilitates. To achieve this, it requires detailed ethnographic, morphological analysis of specific legal works drawn from experience and knowledge of constitutive works within those actual systems of laws, current and historic. The first stage of this methodology is the ontological component in (2) above, where the five basic HIC 1-5 of the applicability criteria, are used to evaluate a presumptive law-candidate for applicability of the LCATH to that work. Naturally, one could apply the LCATH to any work within any regulatory social system, (e.g. a Country Club rule prescribing wearing a tie at dinner) but the function of the identifiers is one of theoretical efficiency in individuating legal action type. That a given work is a legal work is differentiated by scraping its distinguishing indexing criteria obtained by applying the heuristic metaphor of the LCATH. In a reverse analytical loop, this operates as a critique back upon the LCATH itself, refining it structurally as the best explanation for a unified concept of law. This process is repeated for any presumptive systemic law-candidate and the indexing criteria of determined legal works and systems scraped for analysis. As contingent, commensurable truths about each unique legal work within a given systemic network, transcultural and historical comparison of legal works is thereby made possible, while simultaneously critically reviewing the conceptual heuristic LCATH itself.

What then are the primary indexing criteria, scraped from works within the Anglo-U.S. legal systems by applying the LCATH, that together provide a best explanation of law in these systems and for the concept of law generally?

"'Law' is an artistically valuable compound action type, whose enacting actions are its tokens. As action type it is a dynamic, variable form of dramatic enactment in which text and power are dominant ICs. As drama it employs developed costume and scenery elementally integrated into a single legal 'work' within an architecturally sympathetic performance space. As a HCP it is a strongly systemic, stylistic work, integrated through audience, observer engagement, within which multiple works may share common provenance. Multiple works of common provenance constitute a 'legal system'."(Law as Art, 1996: Introduction)

The following observations are insightful at this point.

First, in Boden's classification (1990), all creativity is of three distinct types: (1) exploratory; (2) combinational and (3) transformational (discussed in Du Sautoy, 2019: 7-15). Exploratory, is exemplified by finite group classification in mathematics and in art, by the music 
of Bach. Take existing knowledge and stretch it to its logical limit while staying within the rules. Combinational creativity takes two or more different structures from distinct fields and finds ways to combine them. The rules from one can suggest a radical new framework for another. Du Sautoy (2019) does this by applying prime number theory to geometric objects and in music, Iannis Xenakis composed works entirely within the rules of mathematics, not classical harmony and tonality. The third creativity, transformational, is that rarity of occurrences: The game changing moment. In mathematics, this is well illustrated by the 16th century creation of the square root of minus one and in art, by the cubism of Picasso and Braque. The LCATH of Law as Art (1996) is a paradigmatic example of a multi combinational creative legal theory, with explanatory aspects and transformational aspiration.

Second, In a recent retrospective, The Realist Turn in the Philosophy of Science, Psillos (2016) is unequivocal in affirming the truth of the realist position-the 'New Realism' of the LCATH. Psillos concludes that, in over forty years of new realist theory, the primary claim has been proved, that it does provide epistemic access to observable nature (Psillos, 2020: 20). The only question remaining to be evidenced is: Does this access apply to all aspects of nature or only certain aspects? Law as Art and the LCATH generated, is an extended argument that such access applies to the observation of legal phenomena and their social-legal systemic networks.

Third, the LCATH is a combinational creative theory, the realist framework of which has been demonstrated to provide epistemic access to legal phenomena. It claims to be the best explanation so far, for such phenomena. Since Law as Art was written (1996), the literature on this explanatory metric has continued to develop. Delsen (2020) has recently applied an additional criterion to inference to best explanation. This avoids ever having to select the best available explanation as a sufficient, but weak, epistemic standard.

"Best explanation needs to meet the test of 'good enough' and the author uses the idea of 'explanatory consolidation' to express this standard." (Delsen, 2020: 26)

This counters the critique that differentiating the plausible from the best inferred explanation can vary from unproblematic to unworkable. That is, if the only measure is some minimum balance of explanatory criteria. The concept of explanatory consolidation is interestingly congruent with the overarching combinational creativity of the LCATH.

"I have suggested that a hypothesis becomes 'good enough' when it has been through explanatory consolidation, a process in which direct empirical evidence for the hypothesis, and repeated failures to come up with plausible alternatives, gradually accumulate so as to support the optimistic explanation that the reason we haven't found a better explanatory hypothesis is that there is no such hypothesis to be found. Although this is a highly fallible process, to be sure, I have argued that it is both more epistemically secure and more descriptively accurate than the standard model of IBE in which one simply infers to the best explanation one has thought of so far." (Delsen, 2020: 26-7)

Therefore, the LCATH in Law as Art (1996) is now revised to incorporate Delsen's hypothesis, as a working criterion, as it enhances applicability and adds epistemic weight to the metric. That the LCATH is the best explanation for the concept of law, is now to say that it is 'good enough', having satisfied the evidential criterion of 'explanatory consolidation'.

To conclude this exposition of the new realist LCATH, it remains to differentiate it from 
the recent 'naturalist turn' in the legal theory of Leiter $(2007)$ and Tamanaha $(2001,2015,2017)$ in the U.S. The overarching thesis presented by Leiter in the edited collection Naturalizing Jurisprudence: Essays on American Legal Realism (2007), is a reinterpretation of the American Legal Realists as prescient philosophical 'naturalists' within the scientist tradition of Quine (1990) and Putnam (1990). It considers modern legal theory to be a binary choice between naturalism and an analytical conceptualist hermeneutic. Before considering the argument, it can be noted that the LCATH rejects Leiter's binary as presented. It substitutes for the analytical hermeneutic, the heuristic of the LCATH as cluster property. All hermeneutic insight is not rejected, just incorporated within a multi-combinational conceptual structure. Notwithstanding this conceptual disparity, as both the LCATH and the naturalist turn are realist legal theories, there are significant points of coherence.

So what precisely is the naturalist turn, for Leiter? Building upon the philosophical scepticism of Quine (1990),

“...there was a 'naturalistic turn' in English-speaking philosophy from the 1960s onward, that is, a recognition that to illuminate philosophical questions about knowledge, mind and moral motivation..., it would be necessary for philosophy to proceed in tandem with the sciences, acting as the abstract, reflective, synthetic branch of empirical science." (Naturalizing Jurisprudence, 2007: 3)

LCATH is in agreement, but the question remains: Where is Law best located within this naturalistic world view? Leiter proposes a reinterpretation of American Legal Realism as best 'fit' with naturalism. That is why they are claimed to be prescient naturalists, offering the possibility that

"...perhaps even questions about the nature of law itself might be settled by the results of the empirical sciences.” (NJ, 2007: 6)

By what method could they be settled? As with the LCATH, the preferred methodology would be an "exercise in conceptual ethnography" (Naturalizing Jurisprudence, 2007: 6). Similar to the descriptive ethnology proposed for the concluding part of the law as art hypothesis: The Art of Law. The implications for legal theory in adopting such a methodology are considered in the Postscript to Part II (Naturalizing Jurisprudence, 2007: 183-203). What could a naturalist turn substitute for this alternative analysis of concepts by "appeals to intuitions"? Following Quine, naturalism requires

“...taking seriously the enormous social scientific literature on law and legal institutions to see what concept of law figures in the most powerful explanatory and predictive models of legal behaviour..." (Naturalizing Jurisprudence, 2007: 184)

The LCATH concurs but asks: How can the systemic concepts of law experienced be differentiated or identified as law? Is law just what a self identified legal system claims it to be? How is that differentiable from non-legal systems? How is a comparative, commensurable metaanalysis of the data possible? How can naturalism avoid solipsism? The LCATH does not have to engage this set of issues. It is a heuristic hypothesis that operates to scrape identifying criteria for meta-analysis, without appealing to universalism. The LCATH therefore does follow the naturalist turn in taking issue with the orthodoxy, that a legal theory is one that claims universal truths about law that explain the nature of law. For naturalists, 
“...if you want to know what makes 'law into what it is,' or what makes any $\mathrm{X}$ into what it is, you need to know how Xs are described and explained by the sciences.' (NJ, 2007: 186 emphasis added)

Other than requiring further exploration of the scientific metric in the last phrase, LCATH broadly concurs. It also concurs with the observation that what non-naturalists

"...really believe is that the concept of law is...a 'Hermeneutic Concept,' that is a concept whose extension is fixed by its role 'in how humans make themselves and their practices intelligible to themselves.' "' (NJ, 2007: 186)

If correct, then the reality this hermeneutic reveals, will be different to that revealed by naturalism or the LCATH. Leiters counter argument, which the LCATH affirms, is that modern science embraces, not excludes, hermeneutic concepts.

"...with the defeat of the logical positivism program, such an assumption no longer makes sense: the positivist picture of there being just one kind of confirmation, one kind of explanation...has been replaced with $\mathrm{w}$ new pluralism that recognizes...that "explanatory adequacy is essentially pragmatic and field-specific." (Naturalizing Jurisprudence, 2007: 187)

The LCATH makes precisely the same argument, as all knowledge is part of a coherent single web of belief. Somewhat suprisingly, Leiter concludes with the possibility that Austin's famous axiom on conceptual analysis could be correct after all,

“... 'We are using a sharpened awareness of words to sharpen our perception of phenomena.'..." (Naturalizing Jurisprudence, 2007: 197)

What Austin and Leiter both overlook that the LCATH explains, is that words are used to sharpen the concepts that facilitate the varying degrees of inchoate epistemic access to real phenomena such as law. The LCATH does concur with Leiters concluding aspiration that naturalising jurispridence will "change the subject" in legal theory. As a multi-combinational creative legal theory, changing the subject is precisely what one would expect from the LCATH. That is exactly what it advocates in a more deeply penetrating and explanatory way than Leiters creatively exploratory revisioning of American Realism as an embryonic naturalism. It also rejects Leiter's implied diminution of positivist legal theory, (indeed, of all legal philosophy), in that it must

“...acquiesce to 'naturalized jurisprudence' and accept Leiter's proposal for a new methodology based on the needs of the social sciences. This would render legal philosophy into a subsidiary role in legal theory more generally: legal philosophy would serve to clarify the concepts applied to law by social scientists." (Burge-Hendrix, 2008: Preface)

This critique of Leiter applies equally to the more orthodox writing of Tamanaha, who also approaches the idea of law from an empirical, socio-legal realist position. If more centrally located within the historic American Legal Realist tradition than Leiters scientifically naturalistic reinterpretation. The core of Tamanaha's reasoning is articulated in two open source papers $(2015,2016)$ and the monograph A Realist Theory of Law (2017). As with Leiter's naturalist turn, the new realist LCATH shares much of Tamanahas general theoretical perspective, but is significantly more structurally complex as an explanatory heuristic. 
In the paper Necessary and Universal Truths about Law (2015), Tamanaha offers a forceful critique of the orthodox analytical position, that any theory of law must consist of necessary and universal truths about law. Drawing upon social philosophy, differentiating natural kinds and social artefacts, the critique is that the claim that universal truths are necessary is not a given. It requires significant reworking of ontological and epistemological theory to convince and this has not been effectively achieved by mainstream analytical universalists. The LCATH concurs and is why Law as Art (1996) includes an exhaustive account of the ontological and epistemological foundations of the concept of law as compound action type. It is interesting that in the principal exposition of his theory (A Realist Theory of Law, 2017), Tamanaha does not himself rework these philosophical pediments. This is best explained by the assumption throughout his work, that he is employing settled socio-legal theoretical concepts. In contrast, the LCATH uses a diverse conceptual vocabulary from its multi-combinational perspective in creating a new legal paradigm. A conceptual framework that necessitates epistemological and ontological reworking.

The principal argument of Tamanaha's paper - that universal application of a legal theory is defensible but universal truth is not - lies at the core of his realist legal theory. He constructs his argument for this proposition upon the classic, Kantian 'is/ought' antinomy, or as phrased

"Universal truth claims cannot be grounded on contingent social historical forms." (Necessary and Universal Truths about Law, 2015: 17)

In the LCATH, there can be no universal truths, only theory saturated, contingent empirical and normative human propositions about the world. The necessary truth condition of classical analytical philosophy falls. Having successfully affirmed the contingency of socio-legal realism, the next issue is: What then is law for Tamanaha? Along with Leiter's naturalist turn and the LCATH, Tamanaha's realist theory of law rejects the necessary truth thesis of orthodox analytical theory. Their minds are closed

"...to the possibility that there might be multiple forms of law... ...multiple manifestations of law, each with a collection of characteristics, none essential or necessary and much variation among them... ...a multiplicity of conventionally recognized forms of law..." (A Realistic Theory of Law, 2017: 162-3)

In the same paragraph, following Schauer (2011a), he refers to this "multiplicity" as a "Cluster concept." The LCATH agrees with this critique of orthodox analytical theory and an integral ontological component of law as compound action type is that it is a homeostatic cluster property. This passage could well have been cited directly from Law as Art, which first appeared in 1996 yet is unreferenced in A Realistic Theory of Law.

Much of Tamanaha's exposition restates mainstream American Realism and accepted socio-legal theory. Law and society are constantly evolving in a reciprocal loop.

"The evolution of society is the evolution of law, and vice versa, conjoined aspects of one and the same process." (A Realistic Theory of Law, 2017: 58-59??)

This is the classical legal realist observation that law is a social phenomenon. More precisely, legal systems are social phenomena, whereas for the LCATH the idea of Law is a human brain concept, either inherited biologically or as preferred, acquired. Laws are actual social 
phenomena with which we build networks when of similar provenance and style. These networks are a neurological construct that we identify as 'legal system'. Tamanaha goes on to make the traditional distinction, based on the incommensurability of empirical and normative reasoning and which the LCATH refutes, that sociological and analytical jurisprudence deal with entirely different problems. A Realist Theory of Law is not a legal theory of necessary truths, but a theory of law as an evolving social phenomenon. The LCATH is a theory of law that does not hold universal necessary truths, but accepts empirical and normative knowledge of law as evolving social phenomena that are neurologically identified as such, whose indexing criteria are commensurable.

Tamanaha restates the orthodox realist conventional theory of law. It is whatever social groups attach the label 'law' to, but

"...general social acceptance must be achieved to become conventional." (A Realistic Theory of Law, 2017: 163)

This begs the further question: What is meant by the metric "general social acceptance"? The labelling process still requires a theory of identification to differentiate legal from non-legal social phenomena. Tamanaha again follows the socio-legal orthodoxy and uses the metric of deeply entrenched folk concepts. Is this another way of describing shared brain concepts? As will be argued, the neurological explanation is a better fit in explaining what these shared concepts are and why it is they are so deeply entrenched. Inherited biologically or acquired neurologically and revised over a lifespan of human sentient experience. A descriptive ethnography of legal folk concepts, scraped from contemporary social systems with the legal label/identifier, genealogically reviewed historically, provides Tamanaha with three abstracted criteria.

“...1) fundamental rules of social intercourse, addressing property rights, personal injuries, enforceable obligations, control over labor, and rights and responsibilities with respect to family unions and children; 2) institutionalized rule systems administered by a polity backed by coercion; and 3) Justice, fairness, and right. Conventional identifications of law usually attach to phenomena with one or more of these three connotations; because they are weighty, the label 'law' is not easily attached conventionally to new phenomena." ("A Realistic Theory of Law, 2017: Conclusion)

These three basic criteria of prima facie legality can be compared with the hypothetical indexing criteria of the LCATH, HIC 1-5. The substantive differences reflect the two quite distinct heuristics by which they are arrived at and the function they perform. Tamanaha has carried out an ethnography of a particular legal culture. The three are common criteria for applying the legal label historically in that culture. A major concern is how much of each of the three criteria is essential to qualify the system as a legal system? Tamanaha can only resort to a metric of intuition or weight. The very metric that was critiqued when used by analytical jurisprudence. Furthermore, it is in no way clear what utility these criteria have for our understanding of the idea of law, other than to describe what a specific culture states amounts to law. There can be no transcultural application, as the criteria are an abstraction from culturally distinct, real social systems. Tamanaha is correct to say that he has not presented a legal theory. He has restated the socio-legal empirical methodology of the American Realists. A descriptive ethnography, abstracting common differentiating criteria in order to understand more deeply the criteria of legality in a self-defined legal culture. 
The hypothetical identifiers of the LCATH are scraped indexing criteria, but they are not an abstract reduction. Since labelling as law is always inchoate, there is no de minimis quantum of qualifying criteria. Tamanaha's three criteria are system specific. The five identifiers of the LCATH are system derived, yet an open set of contingent, substitutable criteria that provide a working heuristic to identify a potential law-candidate. A system that is a candidate for applying the LCATH. Tamanaha's thesis is universally applicable, but not data output commensurable. The LCATH is both universally applicable and data commensurable. The hypothetical criteria are epistemic input efficiency criteria not determinative of legality, as in Tamanaha's thesis. The five criteria are mostly structural, whereas the three folk concepts are largely substantive. This structural quality flows from the complex, creative, multicombinational ontology and epistemology of the LCATH, a framework with no counterpart in Tamanaha's work.

In conclusion, it can be said that A Realistic Theory of Law is a timely restatement of American Legal Realism, with all the strengths and weakness of that historic position. It breaks no new ground, unlike Leiter's 'naturalist turn' which does, by seeking to relocate American Realism within late 20th century scientism. In so doing, it illuminates the potential of a relocation of legal theory deep within and across the wide spectrum of innovative theoretical development in science. As shall be demonstrated, that is precisely what the LCATH sets out to achieve, especially in neurobiology and post-Quantum Pattern, System, Network and Complexity theory. It does so without Leiter and Tamanahas unjustified subordination of legal philosophy within the social sciences. Having restated the LCATH as concept of law and differentiated it from the legal theory of Leiter and Tamanaha, it will be further restated in light of recent important developments in brain science.

\section{Part II: Law, Vision and Contemporary Brain Science.}

The consideration of key legal literature since Law as Art was published in 1996, illustrates the combinational creativity of the LCATH as a concept of law. Since publication, the domain of brain science has undergone fundamental theoretical development. Developments with important implications for the ontological and epistemological components of the LCATH. The work with the most impact for the LCATH is by Zeki, in his explanation of the brains visual cortex (1993, 2001, 2009). Also of significance is the analysis of neuro-epistemic reductionism in art and brain science, in the work of Kandel (2016) and not least, Manderson's fascinating, innovative idea of "imaginal law" (2018).

Semir Zeki is generally regarded as the global expert on vision and the brain. Until relatively recently, if a non-scientist wanted an explanation of the associative brain states to human consciousness, learning and memory, they would-in Zeki's opinion-be better directed to

"...the poetry of Shakespeare or the music of Wagner, both of whom might be considered... ...amongst the greatest neurologists." ('Zeki, 1993: 1) 
The LCATH indebtedness to Wagner affirms this analysis. Zeki's research has now made possible a neurobiological answer to this question, one supported by data.

"Knowledge cannot be acquired without consciousness. We can...now...say that consciousness and the acquisition of knowledge are features of certain neural organizations concerned with colour vision," ('Zeki, 1993: 356 emphasis added)

Concerned with colour vision, not with a matrix of all five major senses. In ways still not yet fully explicable, the other four senses, functioning as distinctive data sensors, collaborate with the visual cortex to construct brain concepts through which all knowledge is constructed and shared. This includes knowledge associated with those non-visual senses, such as the smell of coffee of the sound of a dog barking. Zeki's subsequent research has taken him even deeper in understanding how these neural organizations can be explained.

To understand his position, it is useful to take a step back to a critical determining aspect of Darwin's evolutionary thesis. What Darwin called "variability."

"Charles Darwin argued in The Origin of Species that variability, one of the chief determinants of evolution, is greatest in structures that evolve fastest. In humans, the brain is the most variable and fastest evolving organ. We cannot at present ascribe this variability to any well-defined structure or component in the brain. Rather, we infer it through the wide differences in, for example, intelligence, sensitivities, creative abilities, and skills. Art is one expression of this variability... Variability confers huge advantages: it enriches our cultures immeasurably and is a key factor in the further evolution of human societies. Yet, as an evolutionary imperative, it also exacts a high price. It is often the cause of serious injustice and marginalizes from society those whose conduct or inclinations are judged to be deviant from the norm." (Zeki, 2001: 51)

The crux of this argument is that what we call Art, is a human expression of Darwinian variability. This has been discussed at length in Law as Art (1996: Part I), but importantly, Zeki's observation supports the LCATH selection of an artistic heuristic metaphor for the best explanation of the concept of law. For Zeki, it is through a future charting of this variability that the importance of art to law will ultimately be explained. Law as a brain concept, derived from our shared experience of the inherited, perfectionist, variability engaging concept of art.

"Art renders the destructive, isolating, and individualizing effects of variability safe in its pages, canvasses, and scores... These artistic studies of variability have had little social or legal implications. But when neurobiology starts charting the neurological foundations of variability, the results will affect profoundly our social organization at all levels, including the educational, political, and legal... we do not acknowledge sufficiently, if at all, the extent to which that subjectivity and variability is based upon a commonality. It is commonality that allows us to communicate about art and through art." (Zeki, 2001: 52)

In an Important passage for the LCATH, Zeki uses Wagner to illustrate this artistic communication. He then concludes with a vision of future implications for this research, a vision he was clearly unaware had already been articulated for legal phenomena in Law as Art (1996).

"Richard Wagner, seemingly never finding his ideal romantic attachment, wrote Tristan und Isolde as the 'greatest monument to the greatest of all illusions, romantic love.' But an 
illusion is a construct of the brain. Here, the impossibility of ever finding, in individual romantic attachments, the ideal romantic conditions constructed by his brain is emphasized by the belief that only in death can this be achieved... ...I therefore hope that neuroesthetics will broaden to tackle other issues, such as the neural basis of religious belief and the relation between morality, jurisprudence, and brain function-questions that are fundamental in man's quest to understand himself. Like art, these play a critical role in our lives and are also subject to the quality of variability that is at the heart of our civilization. I shall be surprised if such an understanding does not modify radically our view of ourselves and our societies." (Zeki, 2001: 55)

Zeki concludes by arguing, that for human variability,

"...visual art... ...obeys the laws of the visual brain, and thus reveals these laws to us. Of these laws, two stand supreme." (Zeki, 2001: 53)

The two interconnected scientific laws are; constancy and abstraction. Both have important implications for the LCATH. Zeki's most recent and most important work on this subject, is Splendour and Miseries of the Brain (2009). In its account of brain concepts, we have an important supplementary component to augment the LCATH as originally constructed. Zeki's principal thesis

"...is that a central and primordial function of the brain is the seeking of knowledge and that it does so through the formation of concepts. Nor is this concept formation limited to abstract knowledge; it is instead a ubiquitous operation that the brain performs continuously throughout post-natal life, on almost everything that it encounters... ...This seemingly effortless capacity, which is supported by a neurological machinery of immense complexity, is a splendid evolutionary triumph of neural engineering, allowing the brain not only to obtain but also to generalize its knowledge. But there is often a heavy price to be paid in return for this exquisite capacity, which is that of misery." (Zeki, 2009: 16)

For Zeki, art, love and beauty are examples of abstract ideas that correlate to highly specialised brain function. Therefore,

"We may thus say that, hand in hand with every specification in the functions of a cortical area goes an abstraction; indeed abstraction is the inevitable by-product of specification. That the capacity to abstract is ubiquitous in the cerebral cortex is just as important when it comes to considering the brain as a knowledge-acquiring system, as we shall see below. Perhaps paradoxically, specification and abstraction are two sides of the coinage of acquiring knowledge. Knowledge cannot be acquired, at least not efficiently, if either property is missing." (Zeki, 2009: Ch.1)

This is not the only kind of brain abstraction. Another, fully intertwined, emphasises

“...the general at the expense of the particular. This latter kind of abstraction is the basis of what is known as perceptual constancy... Together, these two forms of abstraction emphasize the fact that a ubiquitous function of the cerebral cortex, one in which many if not all of its areas are involved, is that of abstraction" (Zeki, 2009: Ch.1)

Two laws of the specific and the general: perpetual constancy and abstraction. The first emphasis the abstract over the specific - the second references the abstract to the specific. Zeki then differentiates two kind kinds of brain concept: inherited and acquired, or synthetic. 
"Acquisition of knowledge is a principal function of the brain, and the brain does so in a seemingly highly efficient way. The efficiency is due in no small measure to the use of concepts, of which there are two kinds, inherited and acquired. These two kinds are intimately linked and indeed one could not exist without the other. The inherited concepts organize the signals coming into the brain so as to instil meaning into them and thus make sense of them. The acquired concepts are generated throughout life by the brain, and make it significantly independent of the continual change in the information reaching the brain; they make it easier for us to perceive and recognize and thus obtain knowledge of things and situations... All knowledge is brain knowledge." (Zeki, 2009: Ch.1)

A perfect illustration of an inherited concept is

“...regulating the generation of color by the brain," (Zeki, 2009: Ch.1)

“It is rooted in a golden rule of perception, namely comparison."(Zeki, 2009: Ch.2)

A further distinctive quality of this human colour system is its autonomy.

"...the application of the brain programs to the incoming signals does not depend upon the healthy functioning of the rest of the brain or even the rest of the visual brain" (Zeki, 2009: Ch.3)

Love and beauty are other inherited examples. The 'unity in love' Romantic concept in Wagner's oeuvre, notably in Tristan und Isolde, reveals both the limitations of such a concept and its 'severability'.

Inherited and synthetic concepts are critically linked, in that Inherited brain concepts are "precursors" of SBCs (Zeki, 2009: Ch.3).

"The knowledge-acquiring system of the brain is thus very widely distributed in the cerebral cortex. This means essentially that many cortical areas, both visual and non-visual, are also involved in the formation of synthetic brain concepts... But herein lies an important difference between inherited and acquired brain concepts. Whereas inherited brain concepts are intimately linked to specific areas, with the internal machinery of each area being necessary to organize the incoming signals in a particular way, depending upon its specialization, there is every reason to suppose that acquired brain concepts are strongly dependent upon influences from other, often 'higher,' areas. This is because judgment, past experience, and memory all play critical roles in updating the synthetic brain concept and modifying it with time." (Zeki, 2009: Ch.4 emphasis added)

The synthetic brain concept is "modified...with time". Unlike those inherited, they can be discarded completely. The LCATH is amended to incorporate Zeki's binary thesis on brain concepts. It now holds law to be a synthetic brain concept, drawing on an extensive range of autonomous processing areas of the human brain. The idea of law is predicated upon human inherited concepts and modified through time by incommensurable sentient experience. It can be discarded within de minimis social groups or when living alone or substantially discarded in time of total war. Zeki's thesis accounts for the cluster property quality of the LCATH and compound structure of all legal works, that when engaged, generate unique individual experiences. Synthetic concepts are conceptual cluster properties. They also account for both the diversity and similarity of indexing criteria between human legal systems. 
Synthetic concepts are formed

“...through a marvel of neural engineering, [that] also has strict limitations. The concepts formed are synthetic ones, dependent upon the continual acquisition of experience throughout post-natal life. But the momentary experience is of particular examples only, which commonly fail to satisfy the synthetic concept in the brain..." (Zeki, 2009: Ch.2)

One can apply this to the Wagnerian 'unity in love' as an inherited concept, noted above. In Tristan, Wagner shows how the inherited brain concept of Romantic love, leaves the lovers lives shattered through their traumatic realisation that it is not attainable in life. Only conceivably in death. As Zeki poignantly expresses it

"...without understanding something about the concept-forming capacities of the brain, one will fail to comprehend what is at the root of much of human misery" (Zeki, 2009: Ch.2)

To briefly recap.

"To obtain knowledge of this world, the brain must categorize objects and situations and form a concept of them... ...the formation of acquired concepts also involves abstraction... Acquired brain concepts are distinct from inherited ones in that they are developed by the brain throughout its post-natal life and are therefore capable of being continually modified... To develop the acquired concept throughout post-natal life depends upon the acquisition of new experience and incorporating it into earlier experiences. Memory and judgment, which allow for the capacity to compare the new experience with previous ones, are obviously critical factors here. Hence we find that, unlike the inherited brain concepts, the acquired ones are open to wide influences from other brain areas and are critically dependent upon the brain's memory and judgmental systems... How the brain forms concepts is a matter that neurobiology has hardly touched upon." (Zeki, 2009: Ch.5)

Zeki then proceeds to reinforce the non-immutable, modifying quality of any synthetic concept which

“...may change internally, through thought processes in the brain... If inherited brain concepts constitute the organizing principle, thus generating perceptions and therefore experiences, while categories are generated from these experiences through the synthetic, acquired, concepts, it is obvious that the two must be very intimately linked. Indeed, one can say that the former is the basis of the latter, without which the latter cannot exist... ...it could be said that the rule for acquired concepts - a synthesis of many experiences - is to be continually modified. Just as the inherited brain concept is indispensable for generating the experience, so the experience is indispensable for generating the acquired concept." (Zeki, 2009: Ch.5)

Neurobiology has only started to unravel such complex thought processes, but we do know that human creativity is driven by the idea of perfection, the understanding of which revolves around our synthetic concepts (Zeki, 2009: Ch.7). Anyone who has reflected upon Romantic art and literature knows that it is this perfect quality of the inherited concept of 'unity of love' that is at the root of its unattainability in lived experience. Only in the eternity of death. It is an ideal or perfect love, compared to say, the love of a parent for their child.

"This of course raises the fundamental question of how a synthetic concept in the brain is satisfied. There must be some kind of mechanism to indicate that a certain landscape, for 
example, comes close to satisfying the synthetic concept of the perfect landscape. The answer probably lies in the reward and pleasure centers of the brain... Imaging experiments have shown that when subjects rate a painting as beautiful there is heightened activity in part of the reward system of the brain, the orbito-frontal cortex, which itself is only one part of an extensive reward system that involves other cortical and sub-cortical structures... The sources of perfection thus lie in the brain, and more specifically in the synthetic concepts formed by the brain. Synthetic concepts are commonly difficult to experience, particularly since they often depart significantly from the individual experience. One way of getting closer to a brain concept lies in creating a work, be it of art or music or literature. Even here there is commonly a mismatch between the brain concept and the artistic product." (Zeki, 2009: Ch.7)

This is true of Romantic love in Wagner's Tristan und Isolde. It is true in U.S. jurisprudence, of the drafting of the Constitution as a legal work, for giving structure and governance to the Enlightenment ideals of a new political republican citizenry. It is true of Joyce's novel Ulysses, in it's portrayal of the inner and outer narrative of a single day, through a new compound, complex literary prosody. All three bring us closer to their respective conceptual core. All three are frustratingly ambiguous in many ways. All three are incomplete, im-perfect and to some degree, unsuccessful in achieving their objective. All three are nonetheless important works of human creative art.

This raises another quality of brain concepts. Those inherited, are relatively accessible across the species (and therefore commensurable) through individual experience, whereas the synthetic or acquired, often depart significantly from that experience. Synthetic concepts such as law are therefore accessed through the infinite multiplicity of possible experiences. Every experience is of the same work, but to some degree incomplete. There is an inherent ambiguity about the experience of any synthetic concept. This is precisely what the LCATH claims is the case with the action type of law, evidenced in multiple instantiation and expressed through the instance multiplicity hypothesis in Law as Art (1996).

"There is another interesting feature about multiple interpretations,... ...that once evolution hits upon a successful solution it uses it repetitively with such modifications as may be necessary for every new departure... At the other end, the brain uses this same strategy to give multiple interpretations to, for example, works of art." (Zeki, 2009: Ch.8)

A common misunderstanding in art theory is to limit the quality of this ambiguity to the truly 'great' art works. To masterpieces. Rather, ambiguity

"...is a characteristic of the brain in its knowledge-seeking role, a characteristic that the artist exploits and uses to sublime effect and thus enriches his work. Equally, the viewer uses this same potential in providing different interpretations and thus enhances his or her experience of the work" (Zeki, 2009: Ch.8)

It is this repeated ambiguity-a higher or meta-ambiguity—within which our brains construct the concepts it uses to give meaning to the world. As Zeki reminds us,

"One of the functions of the brain,... is to instill meaning into this world, into the signals that it receives. Instilling meaning amounts to finding a solution. But the brain commonly finds itself in conditions where this is not easy, because it is confronted with several meanings of equal validity. Where one solution is not obviously better than the others, the only option is to allow several interpretations or rather to project several interpretations, all of them valid. 
Such a higher level of ambiguity is to be found in the multiple narrative interpretations, or concepts, that can be given..." (Zeki, 2009: Ch.11)

Zeki then cites his earlier paper (1993) to incorporate experience of art within this process.

"...the function of art is an extension of the function of the brain, namely the acquisition of knowledge about the world, and if the brain does so by forming concepts of all that it experiences, then it stands to reason to suppose that the mechanisms used to instill meaning into this world are the very ones used to instill meanings into works of art. It is those basic mechanisms that artists have used in creating their works and it is those same mechanisms that we use to interpret their achievements." (Zeki, 2009: Ch.12)

Using this new theoretical framework, he reveals the essence of Wagner's Tristan und Isolde.

"In a curious way, it is the projection into art of the unrealistic demands of biology, mediated through the agency of inherited brain concepts... Wagner understood instinctively, like Thomas Mann after him, that the concept of love in his brain could not be achieved in life, but only through art... Neurobiologically, and from a neuroesthetics viewpoint, there are three aspects of Wagner's opera that are important. They emphasize in turn the theme of unity or union-in-love, the impossibility of achieving this and that the loved one is in fact a concept in the lover's brain. Also, the musical accompaniment heightens the sense of the unfinished and the ambiguous, thus creating a grand tapestry that encompasses many of the themes of passionate love... Much of the opera can be described briefly, but accurately, as the gradual realization of the impossibility of realizing the concept of a total union of two individuals in love in this world, its annihilation through death remaining the only solution... The brain concept of a total union in love is unrealizable on earth, and can only be dreamed of elsewhere, in a heaven that succeeds life. And so, in the midst of the celebration of love, the death-wish appears..." (Zeki, 2009: Ch.20)

Zeki concludes Splendour and Miseries of the Brain with a comparison of the painting of Cézanne with the music of Wagner.

"Is there not, after all, some similarity between Cézanne uniting a whole canvas but only in the brain of the viewer, in spite of unfinished patches, and Wagner uniting a whole opera in the brain of the listener, despite the repetitive irresolution and ambiguity?... Collectively, they give support to the view expressed in this book, of a clash between synthetic brain concepts and the experience of particulars in daily life. The literature of love and the works of art also tell neurobiology that, by studying these manifestations of the brain directly, it can find evidence for the belief that there are brain concepts in art and in love that can be of inestimable value in learning about the brain and how it functions." (Zeki, 2009: Ch.20)

One of those heuristic concepts. The most pervasive, powerful, complex and socially impactful concept so far devised by the human brain, is the acquired synthetic brain concept of the compound action type of law.

Kandel's recent examination of Reductionism in Art and Brain Science (2016) follows C.P. Snow and Zeki's work on abstraction, aiming 
“...to highlight one way of closing the chasm by focusing on a common point at which the two cultures can meet and influence each other-in modern brain science and in modern art. Both brain science and abstract art address, in direct and compelling fashion, questions and goals that are central to humanistic thought. In this pursuit they share, to a surprising degree, common methodologies... Whereas the artistic process is often portrayed as the pure expression of human imagination, I show that abstract artists often achieve their goals by employing methodologies similar to those used by scientists... Until the twentieth century, Western art had traditionally portrayed the world in a three-dimensional perspective, using recognizable images in a familiar way. Abstract art broke with that tradition to show us the world in a completely unfamiliar way, exploring the relationship of shapes, spaces, and colors to one another. This new way of representing the world." (Kandel, 2016: Introduction)

His central premise, exemplified by the painting of J.M.W. Turner,

"...is that although the reductionist approaches of scientists and artists are not identical in their aims-scientists use reductionism to solve a complex problem and artists use it to elicit a new perceptual and emotional response in the beholder-they are analogous." (Kandel, 2016: Introduction)

The new biological science of 'mind'

"...aspires to a deeper understanding of ourselves by creating a bridge from brain science to art, as well as to other areas of knowledge. If successful, this endeavor will help us understand better how we respond to, and perhaps even create, works of art." (Kandel, 2016: Introduction, emphasis added)

The LCATH argues that legal theory is just such another domain of inquiry. Kandel, citing Frith (2007), affirms one of the central axioms of the new biology,

"Our perception of the world is a fantasy that coincides with reality". (Kandel, 2016: Ch.2)

Therefore our perception of what we call legal reality is just such a fantasy. It is a fantasy because our brains utilise existing conceptual knowledge to make sense of this data, to create pattern, system and thereby meaning of it. It is uniquely our individual fantasy, but it is also a perception of legal phenomena. The biocentric physics of Lanza, Berman and Pavšič $(2009,2016$, 2020) goes further, collapsing all space, time and reality into a unity of consciousness observation. So the fantasy is the reality. The LCATH shares the biocentric ontological creativity of the conscious observer, deferring the deeper question of a unified conscious dependents reality. That phenomena are legal is therefore determined by our prior conceptual knowledge of the concept of law, according to the accepted hypothetical indexing criteria. As such, our propositional reporting of these sentient, legal facts is commensurable. A dialogue through within we cohere, create our contingent truth about that reality.

Kandel develops Firth's succinct exposition of this process in action.

"Perception incorporates the information our brain receives from the external world with knowledge based on learning from earlier experiences and hypothesis testing. We bring this knowledge-which is not necessarily built into the developmental program of our brain-to bear on every image we see. Thus when we look at an abstract work of art, we relate it to our entire life experience of the physical world: people we have seen and known, environments we have been in, as well as memories of other works of art we have 
encountered... We do not have direct access to the physical world. It may feel as if we have direct access, but this is an illusion created by our brain. (Frith 2007)...

In a sense, to see what is represented by the paint on a canvas, we have to know beforehand what sort of image we might expect to see in a painting. Our familiarity with the natural environment, as well as with centuries of landscape paintings, helps us to discern almost immediately a wheat field in the brushstrokes of Vincent van Gogh or a lawn in the Pointillist dots of Georges Seurat. In this way the artist's modeling of physical and psychic reality parallels the intrinsically creative operations of our brain in everyday life." (Kandel, 2016: Ch.2)

Kandel follows Zeki in conceiving vision as

"...the process of discovering from images what is present in the visual world and where it is." (Kandel, 2016: Ch.3)

It is in this way that vision reveals external reality by processing our internal sentient data/ facts. It reveals a sense of 'what' is there and 'where' it is located. It could not make sense of without a lifetimes accumulation of coherent, accepted conceptual knowledge. Yet it's not just vision working alone. Modern brain science has revealed multiple brain regions specialised for vision that are in fact activated by touch, so that

"Combining information from several senses is critical to the brain's experience of art... In addition to their interaction with each other, vision and touch, both alone and in combination, are capable of recruiting the emotional systems of the brain. These consist of the amygdala, which orchestrates emotions, both positive and negative; the hypothalamus, which executes and makes us feel emotion; and the dopaminergic modulatory system, which enhances the appreciation of emotion..." (Kandel, 2016: Ch.3)

In summary, sensory data (facts) that are the epistemic input to create knowledge (truths), come from our sense of vision, primarily that of colour cones, secondarily that of our brightness rods. Vision is reinforced dominantly by the primary sense of touch with the support from the other twelve currently identified human senses. From this information about reality (of 'what' and 'where') our prior conceptual knowledge makes sense (i.e. generates patterns and systems) of this data that cohere with prior knowledge, to construct rational truth-candidates for commensurable verification. From specificity (both data and neurological specialisation) and abstraction (both perpetual constancy and specific abstraction), drawing on both inherited and synthetic brain concepts, knowledge emerges. Abstraction occurs at the highest level of topdown brain processing and the associated ambiguity is an indicator of our brain seeking knowledge about the world around us. This abstraction process is strongly associated with our emotions, imagination and creativity. With creative art. With law as a distinctive synthetic concept and a compound cluster property of an action type. This is why theory and philosophy are critical to all human understanding of reality, along with experimentation and verification. The specific and the abstract are both prerequisites for human knowledge.

Having differentiated the LCATH from the realism of the contemporary 'naturalistic turn' in Leiter and Tamanaha, a fitting coda is to show how it also differs from the aesthetic legal theory of Manderson (Manderson, 2000, 2012, 2018). His seminal work is the lyrical Songs without Music (2000). Manderson's thesis shares with the LCATH rejection of reducing legal experience ontologically to a system of rules or norms. 
“...by treating a text, legal or otherwise, as if it were merely a sequence of logical propositions, readers miss its formal and symbolic meanings. Creatively using music as a model, he demonstrates that law is not a sterile, rational structure, but a cultural form to be valued and enhanced through rhetoric and metaphors, form, images and symbols." (Manderson, 2000: viii)

"Songs without Music is about the aesthetic dimensions which lie at the heart of law and justice. Aesthetics is the faculty which reacts to the images and sensory input to which we are constantly exposed and which, by their symbolic associations, significantly influence our values and our society. 'Legal aesthetics' suggests that the discourse of law is fundamentally governed by rhetoric, metaphor, form, images, and symbols.” (Manderson, 2000: ix)

Manderson mirrors the LCATH, in being a tripartite thesis, comprising: 1) an aesthetic methodology, 2) epistemology and 3) the idea of "taking aesthetics seriously" (Cf. Dworkin, 1981)

"...taking aesthetics seriously is shown to have normative implications. If we thought that symbolism and imagery were not just failures in law's rationality but part of it's power, what would the legal system look like? The thesis contrasts a variety of modern legal theories and argues that each show a commitment to particular aesthetic values. I conclude by attempting to conjoin the ideas of legal pluralism with the changing aesthetic tenor of the times, in order to find new approaches to law and new metaphors through which to give them life...

These dimensions are developed using a range of analytical tools of growing significance in legal theory, including semiotics, legal history, literary studies, and poststructuralist philosophy. " (Manderson, 2000: ix)

From the LCATH perspective there are two obvious points of coherence. First, it too takes law to be a differentiable form of art work and therefore takes legal aesthetics very seriously indeed. Second, it also seeks "new approaches to Law and new metaphors through which to give them life." They are just quite different artistic forms with a different set of metaphorical heuristics. There is no aspect of Manderson's tripartite theoretical structure that is reflected in the LCATH's ontological, epistemological and morphological components. His concept of law as text subsumes legal experience into a class of text similar to, but differentiable from, other types of artistic text. It subsumes legal text within the act of aesthetic interpretation and legal argument is an incommensurable subjective narrative. We are back to the solipsistic poststructuralism of Derrida and Foucault and legal theory is just a sub genre of Law and Literature studies. Manderson reduces law, not to rules or norms, but text.

In his consideration of Law as Art (Manderson, 2000: 32), he dismisses the thesis without engaging it. Not unsurprisingly, as these are theories with completely different philosophical foundations. Manderson reduces law to aesthetic text and legal inquiry to subjective talk about law. The LCATH seeks to explain the entirety of human experience of real legal phenomena, offering a non-universal heuristic to account for that experience, commensurable beyond context. It seeks to explain the diversity and complexity of law, not to abstract it to a single universal indexing criterion.

The LCATH is a concept of law quite unlike that of Manderson's, yet his work does present an important reaffirmation of the connection between law and art. In a later edited 
collection (Manderson, 2018), he stresses the strong correlation between law and the visual. Visual legal studies, or in his words: "imaginal law" (Manderson, 2018: Introduction). The visual and has already been argued (following Zeki) as essential to the generation of all conceptual knowledge, including that of legal phenomena. The LCATH offers a strong explanatory heuristic for the key insights "imaginal law" reveals about legal reality.

"Foucault has already shown us that in the Renaissance, classical, and colonial periods, social and legal order was essentially thought through variations on the theme of representation. The power of artworks of various kinds to represent legal systems, concepts, and ideologies is a particularly productive avenue for scholarly historical inquiry" (Manderson, 2018: Introduction)

Goodrich implies

"...an uncanny thread connects the liturgical, symbolic, and affective authority of the old legal emblems to the same functions performed by their modern-day descendants - virtual, manipulable and borderless in its variable on-screen environments ... on the mobile optimized web." (Manderson, 2018: Introduction)

Contemporary legal and art works, from the imaginal law perspective

"...share a secret revealed at the moment of their origin: the power of that blank slate, that immanent place of possibility, in both." (Manderson, 2018: Introduction)

Another key insight concerns the impact of new technology.

"In the past century, law's reach has manifestly not lessened but dispersed its effects. This corresponds to a functional dynamic that Walter Benjamin identified as the changing role of the work of art in the age of its mechanical reproduction... Mechanical, not to mention digital, visual media gave new outlets to the representation of law's ideology but also offered law a new and unquestionably powerful set of legal technologies...

...images and visual technologies are not just used by the law. Images are unruly, revealing our legal culture's shocking affective supplement, its excessive and subconscious meaning." (Manderson, 2018: Introduction)

"In certain respects the advent of the digital mirrors the invention and cultural impact of print. One technology introduced linearity, the other pixellation, one ink, the other pulse codes. The early modern era that follows on from the invention of the press indeed witnessed a war of images... Law was never immune to the violent disputations and legal method borrowed from the theological debates in proposing a scriptural method of textual transmission that paid only marginal attention, peripheral respect to the highly controversial status of images 'in the propagation of belief. In the lawyer's argot, to know the law is not to know the words but the force and power (vim ac potestatem) that underlies all meaning'...

The rhetorical action has always been concerned with the manipulation of images, with bringing to life, making vivid, enacting and performing,... ...new media, the digital with all its current environments, networks, and screens makes the image ever more active, mobile, and present. This would not be interesting but for the boundaries that it breaks, the thresholds it crosses and the openings that it promises." (Goodrich in Manderson, 2018: Ch.2 emphasis added) 
These insights stress the importance of the new technology to understanding the legal work. The growing importance to the concept of law, both of performance as an action type and the indexing criterion of power. The LCATH concurs with the need for artistic insight in contemporary legal analysis.

"On the one hand, the tension between the artist as a symbol of autonomy, and law as a symbol of power, has never been more keenly felt. On the other hand, we have never stood in greater need of art's particular gift - its capacity to radically unsettle conventional wisdom about the world around us - than now." (Manderson, 2018: Introduction)

The LCATH seeks to "radically unsettle conventional wisdom" about the contemporary legal world. Law as a synthetic brain concept making possible the enactment of a unique structure and heuristic, of distinct style and provenance. The next step is to develop this reconceptualisation from brain science within the wider perspective of modern post-Quantum theory.

\section{Part III: Law and Quantum, Pattern, Complexity, System and Network Theory}

It was noted in the Introduction, that the concept of legal art work, the LCATH,

“...incorporates ideas from contemporary scientific epistemological realism, theory of art as action type, the concept of compound art work, contemporary brain science, post QT, Network, System, Pattern, and Complexity theory."

Prior to applying the LCATH heuristic morphologically to explain Anglo-U.S. legal works by scraping their indexing criteria, it remains to consider the explanatory fit of the LCATH within contemporary Quantum and System theory. It is argued here, that the degree of theoretical coherence has increased since Law as Art was published, therefore the LCATH needs to be restated to incorporate the most important developments. A comprehensive analysis of these complex, interconnected concepts is The Systems View of Life by Capra and Luisi (2014). This paradigm shift has changed our understanding of reality and needs further explanation, since it is within this reality shift that the LCATH seeks to operate as the best explanation of law.

Capra and Luisi open by highlighting the interdisciplinary imperative

"...to understand the new systemic conception of life and its implications for a broad range of professions - from economics, management, and politics to medicine, psychology, and law" (Capra and Luisi, 2014: Preface, emphasis added)

Generally stated, it is to understand that

“...all living systems are complex - i.e., highly nonlinear - networks; and there are countless 
interconnections between the biological, cognitive, social, and ecological dimensions of life. Thus, a conceptual framework integrating these multiple dimensions is bound to reflect life's inherent nonlinearity." (Capra and Luisi, 2014: Preface)

A single web of conceptual reality. In an innovative argument, they invoke Capra's prior extension of Kuhn's scientific paradigm model (Capra, 1996) to a social one, defined as

"...a constellation of concepts, values, perceptions, and practices shared by a community, which forms a particular vision of reality that is the basis of the way the community organizes itself." (Capra and Luisi, 2014: Introduction). What the LCATH heuristic reveals as 'law'. What Manderson calls the 'imaginal law.'

Physical reality itself becomes transformed through non-Cartesian Quantum theory.

"In quantum theory individual events do not always have a well-defined cause... We can never predict when and how such a phenomenon is going to happen; we can only predict its probability... Whereas in classical mechanics the properties and behavior of the parts determine those of the whole, the situation is reversed in quantum mechanics: it is the whole that determines the behavior of the parts...

The crucial Quantum feature is that the observer is not only necessary to observe the properties of an atomic phenomenon but is also necessary even to bring about these properties. My conscious decision of how to observe, say, an electron will determine the electron's properties to some extent...

There is stability, but this stability is one of dynamic balance, and the further we advance into matter, the more we need to understand its dynamic nature to understand its patterns." (Capra and Luisi, 2014: Ch.4.2)

The importance of the observer as constitutive of conceptual reality has its mirror in the ontological function of the human actor in creating the legal work as action type. An apparent stability through dynamic balance, is reflected in the open, incomplete, stasis of the LCATH as ontological cluster property. Quantum theory emerged

"...during the first three decades of the twentieth century by an international group of physicists including Niels Bohr from Denmark; Max Planck, Albert Einstein, and Werner Heisenberg from Germany; Louis de Broglie from France; Erwin Schrödinger and Wolfgang Pauli from Austria; and Paul Dirac from England. These men joined forces across national borders to shape one of the most exciting periods of modern science, one that saw not only brilliant intellectual exchanges but also dramatic human conflicts, as well as deep personal friendships, vividly portrayed in Heisenberg'...snarratives." (Capra and Luisi, 2014: Ch.4.2)

It is a non-Cartesian mechanics of mathematical probability. Mathematical patterns and complexity now integral to reality. Integral also to the new realism within which the LCATH emerges.

"The resolution of the particle/wave paradox forced physicists to accept a situation that called into question the very foundation of the mechanistic worldview - the concept of the reality of matter. At the subatomic level, matter does not exist with certainty at definite places, but rather shows 'tendencies to exist,' and atomic events do not occur with certainty at definite times and in definite ways, but rather show 'tendencies to occur.' In the 
formalism of quantum theory, these tendencies are expressed as probabilities and are associated with quantities (i.e., mathematical functions) that take the form of waves; they are similar to the functions used to describe, say, a vibrating guitar string, or a sound wave. This is how particles can be waves at the same time. They are not 'real,' three-dimensional waves like water waves or sound waves. They are 'probability waves' - abstract mathematical quantities with all the characteristic properties of waves - that are related to the probabilities of finding the particles at particular points in space and at particular times. All the laws of atomic physics are expressed in terms of these probabilities. We can never predict an atomic event with certainty; we can only predict the likelihood of its happening." (Capra and Luisi, 20124: Ch.4.2)

It is a holistic, probabilistic formalism, not a domain specific, universal one. A contingent reality generating a contingent knowledge of that reality. Parallel to this emerging new formalism

“...high-speed computers, ...allowed scientists and mathematicians for the first time to model the nonlinear interconnectedness characteristic of living systems, and to solve the corresponding nonlinear equations."...

From these models the outlines of a coherent theory of living systems, together with the proper mathematical language, are now emerging. This emerging theory - the Systems view of life...

...the Zeitgeist ('spirit of the age') of the early twenty-first century is being shaped by a profound change of paradigms, characterized by a shift of metaphors from the world as a machine to the world as a network". (Capra and Luisi, 2014: Introduction)

Cartesian machine is replaced in Systems theory by a 'network of networks'.

"Systems thinking means a shift of perception from material objects and structures to the nonmaterial processes and patterns of organization that represent the very essence of life. We should also add that the emphasis on relationships, qualities, and processes does not mean that objects, quantities, and structures are no longer important. When we talk of shifts of perspective, we do not imply that systems thinking completely eliminates one perspective in favor of the other, but rather that there is a complementary interplay between the two perspectives, a figure/ground shift..." (Capra and Luisi, 2014: Ch.4.3)

The interrelated concepts of Pattern, Complexity and Network theory require some further elaboration. Pattern theory emerges from Quantum's mathematical patterns to explain natural symmetry and asymmetry, or chirality. The new frontier of biomathematics.

"...the twin phenomena of self-organization and emergence create a wide variety of intricate and beautiful patterns in the molecular realms studied by physicists and biochemists - from microscopic micelles, folded proteins, and the DNA double helix to the easily visible tessellations and spirals of Bénard cells and chemical clocks." (Capra and Luisi, 2014: Ch.8.4, emphasis added)

The important concept of emergence will be considered below. The idea of self-organization is often referred to as autopoiesis and can be considered here with the related ideas of structure, organization and process.

"Let us return once more to autopoiesis, the defining characteristic of biological life. In their 
theory, Maturana and Varela (1980) distinguish between two fundamental aspects of living systems: organization and structure. The pattern of organization of any system, living or nonliving, is the configuration of relationships among the system's components that determines the system's essential characteristics. In other words, certain relationships must be present for something to be recognized as, say, a chair, a bicycle, or a tree. The configuration of relationships that gives a system its essential characteristics is what we mean by its pattern of organization.

The structure of a system is the physical embodiment of its pattern of organization. Whereas the description of the system's organization involves an abstract mapping of relationships, the description of its structure involves describing the system's actual physical components - their shapes, chemical compositions...

This striking property of living systems suggests process as a third perspective for a comprehensive description of the nature of life. The process of life is the activity involved in the continual embodiment of the system's pattern of organization. Thus the process perspective is the link between organization and structure" (Capra and Luisi, 2014: Ch.14.3)

Capra and Luisi then show that, in system terms, to understand any social phenomena such as law, requires integrating four perspectives: 1) form (as a network); 2) matter (such as artefacts and texts); 3) process (such as communications) and 1)-3) together leading to 4) meaning or understanding of that phenomena. In their words,

"Integrating the four perspectives means recognizing that each contributes significantly to the understanding of a social phenomenon. For example,...culture is created and sustained by a network (form) of communications (processes) in which meaning is generated. The culture's material embodiments (matter) include artifacts and written texts, through which meaning is passed on from generation to generation." (Ch.14.3)

A social phenomenon is formally a social network, which has its origins in Complexity theory.

"A social network,...is a nonlinear pattern of organization, and concepts developed in complexity theory, such as feedback or emergence, are likely to be relevant in a social context as well. However, the nodes and links of the network are not merely biochemical. Social networks are first and foremost networks of communication involving symbolic language, cultural constraints, relationships of power, and so on. To understand the structures of such networks, we need to use insights from social theory, philosophy, cognitive science, anthropology, and other disciplines. A unified systemic framework for the understanding of biological and social phenomena will emerge only when the concepts of nonlinear dynamics are combined with insights from these fields of study." (Ch.14.3)

So, Complexity theory can accurately be described as: The mathematics of patterns,

"The new mathematics of complexity is a mathematics of visual patterns, and the analysis of these patterns is known as qualitative analysis." (Capra and Luisi, 2014: Cgh.4, Box 4.1)

These are visual patterns, which coheres with the sensory work of Zeki on vision and brain concepts and its significance to the LCATH. What more can be said about networks? The idea emerged in the ecology of feeding relations in 19th century naturalists, extended in the 20th to account for 'food webs'. 
“...systemic thinkers began to use network models at all systems levels, viewing organisms as networks of cells, organs, and organ systems, just as ecosystems are understood as networks of individual organisms. Correspondingly, the flows of matter and energy through ecosystems were perceived as the continuation of the metabolic pathways through organisms." (Capra and Luisi, 2014: Ch.4)

It is important to understand that there is no hierarchy of networks. Networks 'nest' inside other networks.

"At the same time, throughout the same history of philosophy and science, the study of form, or pattern, was always present. It began with the Pythagoreans in Greece and was continued by Leonardo da Vinci, Paracelsus, the Romantic poets, and various other intellectual movements. However, for most of the time the study of pattern was eclipsed by the study of matter until it re-emerged forcefully in our century, when it was recognized by systems thinkers as essential to the understanding of life.

The study of pattern is crucial to the understanding of living systems because systemic properties,... arise from a configuration of ordered relationships. Systemic properties are properties of a pattern. What is destroyed when a living organism is dissected is its pattern. The components are still there, but the configuration of relationships between them - the pattern - is destroyed, and thus the organism dies.

Once the importance of pattern for the understanding of life is appreciated, it becomes natural to ask: Is there a common pattern of organization that can be identified in all living systems? ...this is indeed the case. As the early systems thinkers discovered, the most important property of this pattern of organization, common to all living systems, is that it is a network pattern. Whenever we encounter living systems - organisms, parts of organisms, or communities of organisms - we can observe that their components are arranged in network fashion. Whenever we look at life, we look at networks." (Capra and Luisi, 2014: .Ch.5.3 emphasis added)

Human social systems are both physical and symbolic,

"...shaped by the "inner world" of concepts, ideas, and symbols that arises with human thought, consciousness, and language.

Thus a human family can be described as a biological system, defined by certain blood relations, but also as a 'conceptual system,' defined by certain roles and relationships that may or may not coincide with any blood relationships among its members. These roles depend on social convention and may vary considerably in different periods of time and different cultures" (Capra and Luisi, 2014: Ch.14.3)

"Meaning itself is a systemic phenomenon; it always has to do with context." (Capra and Luisi, 2014: Ch.14.4)

The dynamics of culture are also significant, reflecting

"Our ability to hold mental images and project them into the future not only allows us to identify goals and purposes and develop strategies and designs; it also enables us to choose among several alternatives and hence to formulate values and social rules of behavior. All of these social phenomena are generated by networks of communications as a consequence of the dual role of human communication. On the one hand, the network continually generates 
mental images, thoughts, and meaning; on the other hand, it continually coordinates the behavior of its members..." (Capra and Luisi, 2014: Ch.14.4)

This continual mental generation is the neurological revelation of Zeki's inherited and synthetic brain concepts, including synthetic LCATH. Structure in biological and social systems is

"A central focus of the systemic understanding of life is the concept of organization, or "pattern of organization. In the social realm, however, the concept of organization takes on an additional meaning. Social organizations, such as businesses or political institutions, are systems whose patterns of organization are designed specifically to organize the distribution of power. These formally designed patterns are known as organizational structures and are visually...

The ideas, values, beliefs, and other forms of knowledge generated by social systems constitute structures of meaning, or semantic structures. In modern societies, the culture's semantic structures are documented - that is, materially embodied - in written and digital texts. They are also embodied in artifacts, works of art, and other material structures, as they are in traditional, nonliterate cultures. Indeed, the activities of individuals in social networks specifically include the organized production of material goods. All these material structures - texts, works of art, technologies, and material goods - are created for a purpose and according to some design. They are 'embodiments of the shared meaning generated by the society's networks of communications... (Ch.14.4)

The legal art work of the LCATH is understood as the paradigmatic pattern of organization to distribute power so far to emerge in human society. What more can be said about the Systems concepts of emergence and design?

"This process of emergence involves several distinct stages. To begin with, there must be a certain openness within the organization, a willingness to be disturbed, in order to set the process in motion; and there has to be an active network of communications with multiple feedback loops to amplify the triggering event. The next stage is the point of instability, which may be experienced as tension, chaos, "uncertainty, or crisis. At this stage, the system may either break down, or it may break through to a new state of order, which is characterized by novelty and involves an experience of creativity that often feels like magic. Since the process of emergence is thoroughly nonlinear, involving multiple feedback loops, it cannot be fully analyzed with our conventional, linear ways of reasoning, and hence we tend to experience it with a sense of mystery.

Throughout the living world, the creativity of life expresses itself through the process of emergence. The structures that are created in this process - biological structures of living organisms as well as social structures in human communities - may appropriately be called 'emergent structures.' Before the evolution of humans, all living structures on the planet were emergent structures. With human evolution, language, conceptual thought, and all the other characteristics of reflective consciousness came into play. This enabled us to form mental images of physical objects, to formulate goals and strategies, and thus to create structures by design.

We sometimes speak of the structural 'design"' of a blade of grass or an insect's wing, but in doing so we use metaphorical language. These structures were not designed rather, they were formed during the evolution of life and survived through natural selection. They are emergent structures. Design requires the ability to form mental images, and since this ability, as far as we know, is limited to humans and the great apes, there is no design in nature at 
large.

Human organizations always contain both designed and emergent structures. The designed structures are the formal structures of the organization, as described in its official documents. The emergent structures are created by the organization's informal networks and communities of practice...

"Emergent structures, on the other hand, provide novelty, creativity, and flexibility. They are adaptive, capable of changing and evolving. In today's complex business environment, purely designed structures do not have the necessary responsiveness and learning capability. The issue is not one of discarding designed structures in favor of emergent ones. We need both." (Ch.14.5)

The LCATH as synthetic brain concept is a human emergent structure. Given its capacity to effect social order, regulate society, resolve disputes and distribute power and responsibility, the argument can be made that it is the most pervasive and socially significant emergent human structure to emerge in human history. Before illustrating the application of this legal theory to specific legal works, it remains to consolidate these revisions, restate the LCATH and consider the implications for the associated concepts of legal validity, authority, obligation and system.

\section{Part IV: The Concept of Law Restated}

The concept of law articulated in Law as Art (1996) and summarised in the Introduction, can now be restated to incorporate the theoretical insights discussed in Parts I-III:

- Law as Art is a multi-combinational creative legal theory with explanatory aspects and transformational aspiration.

- $\quad$ The law as compound action type hypothesis - LCATH - is the best (good enough) explanation of law to satisfy the explanatory consolidation evidential criterion.

- It is a heuristic hypothesis that operates to scrape indexing criteria from presumptive law candidates, identified by the system derived, open set of contingent, substitutable hypothetical indexing criteria.

- Law is an inherently ambiguous synthetic brain concept derived from shared experience of the inherited perfectionist variability of experiencing multiple instances of real legal works.

- Individual, incommensurable perception of legal reality is a neurological construct in which our brains utilise existing conceptual knowledge to make sense of this data to create pattern, system and thereby meaning of it.

- $\quad$ Sensory data (facts) epistemically inputting to generate knowledge (truths), comes from 
our sense of vision, primarily colour cones, secondarily from our brightness rods.

- Vision is reinforced dominantly by the primary sense of touch, supported by the other twelve currently identified human senses.

- $\quad$ From this information about reality (of 'what' and 'where') our prior conceptual knowledge makes sense of (i.e. generates patterns and systems) of this data that cohere with prior knowledge, to construct rational truth candidates for commensurable verification.

- From specificity (both data and neurological specialisation) and abstraction (both perpetual constancy and specific abstraction), drawing on both inherited brain concepts and synthetic brain concepts, knowledge emerges.

- Abstraction occurs at the highest level of top-down brain processing and the associated ambiguity is an indicator of our brain seeking knowledge about the world around us.

- This abstraction process is strongly associated with our emotions, imagination, creativity and of law as a distinctive synthetic brain concept, compound action type and homeostatic cluster property.

- Quantum theory has affirmed the importance of the observer as constitutive of conceptual reality, illustrated by the ontological function of the human actor in creating the legal action type as a work.

- An apparent Quantum stability through dynamic balance is also reflected in the open, incomplete, stasis of the law as compound action type hypothesis as ontological homeostatic cluster property.

- Quantum material physics is a non-Cartesian mechanics of mathematical probability whose patterns and complexity are integral to reality and the new realism within which the law as compound action type hypothesis emerges.

- $\quad$ Complex visual patterns of legal phenomena combine 1) form (networks); 2) matter (e.g. artefacts and texts) and 3 ) process (communications) to construct meaning of the legal phenomena.

- The LCATH as synthetic brain concept is an emergent human structure. Given the capacity to effect social order, regulate society, resolve disputes and distribute power and responsibility, the argument can be made that it is the most pervasive and socially significant emergent structure, in human history to date.

As emergent synthetic brain concept, law is structurally and morphologically a compound action type, whose enacting actions are its tokens. As action type, it is a dynamic, variable form of dramatic enactment in which text and power are dominant indexing criteria. As drama, it employs developed costume and scenery elementally integrated into a single legal work, within an architecturally sympathetic performance space. As a homeostatic cluster property it is a strongly systemic, stylistic work, integrated through audience, observer engagement, within which multiple works may share common provenance. Multiple works of common provenance cohere, integrate and organise as a legal system. The theory of law as LCATH, can be expressed as a neurological mind mapping of a differentiable domain of coherent, sentient factual data about a real legal work. 
The synthetic brain concept of the LCATH mind maps factual data from experience of the real work, ethnographically individuating the work as presumptive law-candidate using the hypothetical indexing criteria, then as law, by applying the LCATH heuristic and scraping the primary and secondary indexing criteria identifiers of the particular legal work, thereby enabling the action type of its heuristically distinct structure.

The following points of clarification offer additional insight:

- A work is initially identified as a presumptive legal work by applying the hypothetical indexing criteria.

- As synthetic brain concept, the concept of law is a commensurable, abstract, human neurological phenomenon.

- The legal work is a homeostatic cluster property comprised of real objects, texts, artefacts and actions, constituted in part by third party engagement.

- As there can be no immaculate perceptions, the concept of the LCATH is a priori the engagement of the real work. Every engagement with a work, applies the explanatory heuristic of the LCATH and tests the claim to be the best (good enough) explanation of real legal works. Output may affirm the thesis or generate propositional candidates for conceptual revision.

- $\quad$ Enactment is any set of human sensory activity engaging the structure of legal work, e.g. by arresting a thief, adjudicating the offence in court, observing the crime in action or reading about the crime in a news artefact or official law report. In accordance with the instance multiplicity hypothesis, this enactment is but one instance of an infinite number of equally valid possible instances.

- $\quad$ Applying the LCATH to experience of a work, generates the individuating descriptive criteria of the primary and secondary indexing criteria of that work, along with the $a$ priori presumptive hypothetical criteria.

- $\quad$ Analytical output is commensurable knowledge of the work as a legal work, comprised of all indexing criteria of the specific structure and heuristic enacted.

At this point, it is now possible to use the revised LCATH to reconceptualize key ideas commonly associated with the concept of law: Legal (1) validity; (2) authority; (3) obligation and (4) system.

(1) Legal Validity - The LCATH is strongly systemic, but validity is not a systemic quality, but of the individual work. To say a law is 'valid' is to demonstrate that it is, ontologically, law per se. A real legal work is a phenomenon initially identified by the hypothetical indexing criteria as a presumptive law-candidate, then explicable as such, by the metaphorical heuristic of the LCATH, with regard to the scraped primary and secondary indexing criteria. Legal validity is an inchoate, ontological quality of the instantiation of a legal work.

(2) Legal Authority - The orthodox understanding of Authority within Anglo-U.S. legal theory generally combines some or all of the following distinct sub-concepts: (i) a sense of 'perfective formalism'; (ii) an 'implied justified coercion' regarding enforcement; (iii) some 'ascription of obligating moral value', either to the law or the legal system and most importantly, (iv) an obligation or 'duty to obey' the law, as law. The LCATH does not generate an individuated 
concept of 'authority', but individuates and explains the sub-concepts within the context of the enactment of the work. Leaving the question of legal obligation to be considered in (3) infra, what more can be said of sub-concepts (i)-(iii)?

Legal validity is an inchoate, ontological quality of the instantiation of a legal work. There is no normative sense that one ought to ascribe authority to a work (specific law) simply because it is valid law, i.e is law at all. Validity is in this sense, a formalist thesis. Secondly, the LCATH requires an element of empowerment of the law or collective system of laws. To say that one ought to obey a legal work simply because you will be punished if you do not, is not an argument from authority, just a description of it's coercive indexing criterion. Thirdly, the LCATH and its realist philosophical substructure, epistemologically supports the possibility of both artistic and moral subjective, contingent incommensurable facts about legal works as well as commensurable, contingent artistic or moral truths. These are not generative of any sense of an obligating legal authority, but incommensurable, individual artistic or moral value justifications for personal obedience. Turning to the sub-concept (iv) above.

(3) Legal Obligation - As noted in (2), the LCATH does not appeal to any concept of authority to justify an obligation to obey. Legal obligation, as an alternative to legal coercion, is a subjective response of all who engage the particular legal work. A general obligating provenance will require a shared acceptance of the legal work's value. For example, the Constitutions of MA and the U.S. impose an absolutist theocratic moral canon of 'divinely granted natural rights' (universal moral values) as the final arbiter of legal validity, i.e. for a phenomena to be a legal work. As an atheist or skeptic on moral absolutism, perhaps seeing morality as socially relative and denying the reality of natural, universal human rights, or even just in disagreement with the rights chosen in the canon, one may dismiss such claims to moral value and any associated obligation to obey. If there is a cultural provenance of moral support for the canon, as there clearly is across much of the U.S, then they will be held to be morally obligating and a primary indexing criterion of validity, by a large part of the body politic. They are not obligating simply because they are valid legal works. The LCATH specifically denies the possibility of absolute, universal moral values or truths. Moral truths are real but contingent and socioculturally relevant. It therefore takes issue with the unsubstantiated claims to universality made for the canon in the MA and U.S. Constitutions.

(4) Legal System - Already briefly considered, but worth restating, being an inversion of a core tenet of orthodox Anglo-U.S. legal theory. A legal system is a neurologically integrated network of valid legal works of common provenance and style, structure and originating heuristic. As homeostatic cluster property, law is a strongly systemic, stylistic work, integrated through audience, observer engagement, where multiple works may share common provenance. Multiple works of common provenance are conceptualised as a coherent, integrated and organised legal system. Legal system, like law, is a brain concept.

To illustrate the methodological function of the LCATH and to lay the foundation for a detailed ethnography of disparate current and historic legal systems, this paper will conclude with a short-form ethnography of the crime of taking the property of another without consent in two Anglo-U.S. legal sub-systems: Northern Ireland and Massachusetts. 


\section{Part V: An Ethnography of the Law of Theft and Larceny within the Anglo-U.S. tradition}

How is the LCATH applied? What specific kind of commensurable truth or knowledge about a legal work is generated? To illustrate, contrast the Anglo-U.S. legal systems with respect to the specific act of taking property without consent of the owner. The criminal offence of 'theft' in the U.K., or the old English term 'larceny', as it is still referred to in the U.S. Given the common historical and political heuristic of these two social-legal jurisdictions, the LCATH can be expected to explain both common and divergent identifying criteria of the unique structure and heuristic of the valid legal works within each jurisdiction. It should be recalled, that it was from personal experience and engagement of these two culturally associated jurisdictions, that the LCATH was originally formulated in Law as Art (1996), to express what is here referred to as the human synthetic brain concept of law as compound action type. The sentient, shared experience of both systems generated the contingent, a priori hypothetical indexing criteria used to identify presumptive law-candidates as subjects for applying the LCATH explanatory heuristic.

First, a systemic clarification. As the U.S. and U.K. both consist of distinct, systemically integrated politico-legal systems, the offence of the non-consensual taking of another's property occurs within a specific social-legal sub-system. The U.K. comprises three distinct legal subsystems: England and the Principality of Wales, Scotland and Northern Ireland (N.I.). Scotland is anomalous, owing as much to European Civil Law as English Common Law. The relatively small Northern Irish legal system is preferred for comparison with Massachusetts in the U.S. N.I. is firmly within the English Common Law tradition, yet exhibits structural and substantive differences. Unlike the English system, it is a statutory creation with a written constitution (see Dickson, 2018). The LCATH was used to index the identifying criteria of both, summarised in the short-form descriptive ethnographies in Appendix A and B.

In MA the crime of Larceny is enacted and codified in the Massachusetts General Laws (MGL) Part IV Title 1 ch.266 S.30. The N.I. Law of Theft is enacted in The Theft Act (Northern Ireland) 1969 (c.16), and is a legislative Act of the now prorogued Northern Ireland Parliament. The current orthodox experience of the N.I. legal system is authoritatively detailed in Dickson's The Law in Northern Ireland (2018). From the ethnographies compiled, the following are the main common and divergent indexing criteria of the legal works and their unique heuristics.

\section{A. Common Criteria}

- $\quad$ English Common Law.

- $\quad$ The Common Law adversarial adjudication court style.

- A form of the Doctrine of Stare Decisis or precedent.

- The U.K. derived principle of the Rule of Law 
- A form of the U.K. principle of the Separation of Powers - creating Legislative, Executive and Judicial branches of government as 'checks and balances' on power.

- Written or partially written Constitutions.

- $\quad$ Both N.I. and MA have reserved and transferred powers between their secondary legal jurisdictions and the U.K. Parliament and Federal Government respectively.

- Secondary indexing criteria of rhetoric is dominantly accusatory, persuasive and adversarial.

- Most secondary indexing criteria converge, subject to minor differences in historical heuristic.

- Legal recognition of the ownership of property.

- $\quad$ Crime of Theft and Larceny both created by legislation.

- Text of the crimes of Theft and Larceny are similar, but the five elements of the offence are identical - the (i) 'taking' (ii) of 'property' (iii) 'owned by another' (iv) 'without their consent' $(\mathrm{v})$ 'with the intention of permanently depriving them of it'.

\section{B. Divergent Criteria}

- In MA and the U.S. the court of final jurisdiction on Constutional matters is SCOTUS. In the U.K. it is the Court of Parliament, duly constituted and not the Supreme Court.

- $\quad$ On Separation of Powers - (i) In the U.K. the Prime Minister sits in the Legislature, but POTUS sits in the Executive. Therefore the U.S. civil service is subject to Executive control, whereas the U.K. civil service is largely independent; (ii) All U.K. judges are non-political appointments, selected by a non-partisan, independent Judicial Appointments Commission. The U.S. judges are by political appointment, either directly elected or appointed by the Executive.

- On the Constitution - (i) In the U.S. power ultimately lies with 'We the People', but political power in the U.K. lies with a 'Sovereign Queen sitting in Her Parliament'; (ii) The MA and U.S. Constitutions are unitary, amended legal artefacts and texts. The N.I. regional Constitution is also a unitary, amended legal artefact and text, but the U.K. Constitution - of which it is also part - is a variable set of written texts and unwritten customs and conventions.

- On the secondary indexing criteria of legal style - N.I. and the U.K. are both pluralist, relativistic and formalistic, whereas MA and the U.S. are traditional, with transcendentalist (absolutist) aspects. In short, law in N.I. is a matter of satisfying formal criteria, almost always irrespective of content, whereas in MA and the U.S. law is also 
presumptively formal, yet ultimately validated by conformity with a claimed Divinely granted, universally true canon of substantive, transcendent 'natural human rights' or values.

- $\quad$ On the legal recognition of property ownership - In N.I. and throughout the U.K., the legal protection can be withdrawn at the 'Will of Parliament', whose sovereignty cannot be fettered. In MA and the U.S., the right to property is enshrined in the canon of claimed universal truths in both Constitutions.

- On the enacting form of the offences in MA and N.I. - In MA, the crime of Larceny is enacted in the legislative Code of the 'Massachusetts General Laws' (MGL) whereas in N.I. the crime of Theft is enacted in a legislative Act of the (now defunct) NI Parliament. The difference is that the MA Code on Larceny can be amended and revised without repealing the entire Code, whereas in N.I., although the Act can undergo minor amendment, major amendment will require the repealing of the Act by Parliament and the enactment of a new legislative work in substitution.

These indexing criteria, scraped using the LCATH from the MA and N.I. legal works criminalising taking another's property without their consent, are constitutive of those laws as legal works. All of the scraped criteria above, along with those detailed in the addended shortform ethnographies, collectively represent the principal criteria constitutive of the law in each of the two jurisdictions. Law is a compound cluster property of these elements, revealed by the synthetic brain concept of the LCATH as a distinct structure of unique heuristic. The five elements of the textual description of the offences may be very similar, but the legal works are by virtue of these criteria uniquely differentiable. The enactment of S.30s heuristically unique structure would simply be impossible in N.I., or in NY or CA. The reverse is equally true, in spite of the five critical textual artefactual elements of the crimes being identical. The textual artefacts are the essential libretto or script of the enactment, but the valid law in each jurisdiction is a far more complex compound action type, of a quite distinct heuristic, systemic provenance and style. Consider the following hypothetical:

On a busy public Boston MA street, in daylight, an on-duty police officer witnesses an elderly person struggle to hold on to his cell phone as a youth forces it from his hand and runs off. The officer gives chase, apprehends the youth, arrests her and returns the cell phone to its owner. The youth admits her intention to take the phone and sell it to get drugs. She is a relapsed recovering drug addict, just released from a ReHab Clinic. The case comes before the local Court and the Judge listens to the evidence of the officer, the victim and the Attorney for the accused. The Attorney confirms her client knowingly committed the elements of the offence of Larceny in S.30, was sober at the time of the theft and a recovering addict just released from ReHab. The lawyer goes on to cite precedents in support of her petition that in the circumstances, the Judge hand down a non-custodial sentence and instead make a care order to help her client address her addiction. The Judge decides to follow the precedents of the higher Courts in MA and as it was a first offence and the property returned, is empowered to make a non-custodial suspended sentence of 6 months and a care order sending the accused back to ReHab instead of jail time.

This unique performance, or enactment, of the five elements of the offence of Larceny in S.30 of the MGL can be parsed within the LCATH synthetic brain concept heuristic. As such, the critical 
first observation is that all the actors can be inferred as having conceptual knowledge (of varying cohativity) of the offence of Larceny in MA. Their collective actions reveal this prior awareness of the general proscription in MA laws of taking another's property without consent. The Police Officer, Judge and Attorney have had extensive understanding of the structure and heuristic of S.30 through professional training and practice. The victim struggled to give up their property, struggling to stop it being taken and the youth ran away once having obtained it, an action of consciousness of guilt. The taking of the phone, owners resistance, arrest and evidence of the Officer, Judge's adjudication and sanction and the Attorney's plea on her clients behalf, are all constitutive actions collectively enacting this unique performance of the structure and heuristic of S.30. In addition, the Court building, detaining jail and medical ReHab centre to which the accused was returned, the costuming of the on-duty Police Officer, the Judge and Court Officials, the power of an on-duty officer to make an arrest and power of sitting Judge to adjudicate and sanction, jailer to incarcerate, the drama of the theft, the arrest and Court hearing are all indexing criteria of this enactment of $S .30$ as a valid legal work. The decision to make a non-custodial sentence and care order given the addiction of the accused, all add to the heuristic and reaffirm the structural component of the recognition of an inviolable right to property in both the MA and U.S. Constitutions. The set of enacting actions extends to anyone engaging the incident. The public witnesses on the street, the friends, families and work associates of the primary actors, to whom the narrative is reported, or those watching a TV report of the incident or court case or reading of the theft in the textual artefact of a local newspaper or as a digital artefact online or on social media. With these observers and participants there would be no enactment or performance This descriptive ethnography is unique to the provenance of taking property in Boston MA. The legal validity of S.30 has no relevance outside of this contextual enactment, yet is open to direct comparison to the enactment of S.1 of the Theft Act given a similar hypothetical of a stolen phone on a street in Belfast, N.I. The enactments are of two distinct legal works of heuristically unique structure, within distinct legal systems of works that share commensurable common and divergent hypothetical, primary and secondary indexing criteria.

In traditional Anglo-U.S. legal theory the primary criterion of legal validity in the above hypothetical, is considered the written textual rule in S.30 of the Code, the rational normative proposition it expresses, its systemic status and the coercive power of that rule or system of rules in MA. In Dworkinian legal theory the focus is on the correctness of the judicial outcome in applying the morally obligating principle of a right to property in both Constutions. For cultural realists like Tamanaha and Leiter it is a matter of empirical description of S.30s validity within the socio-legal system of MA. For Hart and Raz of the U.K. Oxford School, the textual rule, the validity of the system of rules of which it is a part and the general power and authority to sanction underpinning the system, are together critical to ascription of legal validity. For both, the validity of the textual rule proscribing theft in S.30 is a priori the act of stealing and determines the duties and obligations of the actors and legal validity of the judicial decision. For the LCATH, the textual element of the offence is just one primary constitutive element of the action type of the enactment of the structure and heuristic of S.30, which in totality is but one instance of the law (legal work) of Larceny in MA. It is the synthetic brain concept of the LCATH, applied to sensory data about S.30 that makes possible the enacting of S.30 as a legal work. The text is constitutive of the enactment of the law in the hypothetical above, not a positivised rule or rational proposition that is applied or enforced. No action type, no instantiation of the law of Larceny. No law of Larceny. 
All the insights American Legal Realism historically present about the enactment of legal roles with specified functions, are relevant and insightful, but with a new ontological significance. Lawyers, judges, witnesses, jurors, accused, police officers, legislators and so forth do not just play a part within the socio-legal cultural context in which the legal work is applied. Rather, they are constitutive indexing criteria of an enacting instance of that work. The law of larceny as a real legal work within the MA legal system, itself a neurological construct from multiple works of perceived common provenance and style.

\section{Conclusion}

This paper is a review and restatement of the theory of Law in Law as Art (Bagnall, 1996), in light of current scholarship and as prolegomenon to an ethnographic analysis of commensurable legal phenomena. Law is a real physical and symbolic social phenomenon. A compound cluster property. Individual legal works combine to form a distinct social network, or 'nesting', explicable within contemporary Quantum, Complexity, Pattern, System and Network theory. Legal works are conceived within an emergent synthetic human brain concept, a neurological mind mapping of a differentiable domain of coherent, sentient factual data, drawn from experience. This mapping enables enactment of the works heuristically distinct structure as an action type. As action type, it is a dynamic, variable dramatic enactment in which text and power are dominant indexing criteria. Text constitutes the legal work the way a libretto does an opera, or a script does a play. Law is the enactment of a heuristically distinct structure capable of an infinite set of equal, inchoate enactments. A work is ethnographically individuated as a law-candidate, using the identifying hypothetical indexing criteria and differentiated as law by the unique primary and secondary legal criteria, scraped using the conceptual heuristic. By Quantum analogy, it structurally integrates through audience, observer engagement, where multiple works can share a common provenance and style. Multiple works of common provenance neurologically cohere, integrate and organise as a legal system.

The synthetic brain concept of Law is arguably the paradigmatic natural Quantum pattern of 'nesting' networks so far to emerge in human society, organized to distribute power and regulate social behaviour. Our sensory perception of this emerging pattern of a legal reality is itself a neurological construct, one that fortunately (for humans) corresponds by degree with the physical world. It is a construct because our brain utilises existing conceptual knowledge to make sense of this data, to create the pattern, system and thereby ascribe meaning to it. It is uniquely our individual construct of sensory engagement with a real phenomena, phenomena capable of multiple engagement and enactment by others. We can and do share our personal constructs, as truths concerning such phenomena. That these works are identifiable as legal works, is an explanatory output of our prior conceptual knowledge of the acquired, synthetic concept of Law as compound action type, applied to a presumptive Law-candidate identified using the hypothetical indexing criteria. As such, our propositional reporting of these sentient, legal facts is commensurable. A dialogue through which we cohere and thereby create our contingent truth about that legal reality. 
The legal theory of the LCATH has three general components: (1) the epistemological; (2) the ontological; and (3) the methodological. How can we know law? What kind of entity is law? How to use the LCATH to get the best explanation of what law is in any given legal system? The first and second were the subject matter of Law as Art (1996), as restated in this paper. The third methodological component requires a further detailed ethnographic, morphological analysis of law across a diverse range of current and historic legal works, identified as presumptive law-candidates by the HIC. This is the proposed subject for a future monograph: The Art of Law.

\section{Bibliography}

Alexy, R. (2008). On the Concept and Nature of Law. Ratio Juris. Vol.21 3:281-99.

Atiyah, P.s. and Summers, R.S. (1987). Form and Substance in Anglo-American Law: A Comparative Study of Legal Reasoning, Legal Theory, and Legal Institutions. Oxford: Oxford University Press.

Badiou, A. (2010). Five Lessons on Wagner. New York: Verso.

Bagnall, G. (2016). Law as Art. $1^{\text {st }}$ ed. London: Taylor \& Francis ebook. https://doi.org $\underline{1}$ $\underline{10.4324 / 9781315250687}$

Binder, G. (2006). Law and Literature. John's Hopkins Guide to Literary Theory and Criticism. Buffalo Legal Studies Research Paper No. 2012-022. Available at SSRN: https: / / ssrn.com/abstract=1932901.

Boden, M.A. (1990). The Creative Mind: Myths and Mechanisms. London: Weidenfeld and Nicolson.

Burge-Hendrix, B. (2016). Epistemic Uncertainty and Legal Theory. $1^{\text {st }}$ ed. London: Taylor and Francis ebook. https: / / doi.org/10.4324/9781315256214.

Burnham, W. (2011). Introduction to the Law and Legal System of the United States. 5th Edition. St. Paul $\mathrm{MN}$ : Thomson Reuters.

Capra, F. (1996). The Web of Life. New York: Anchord/Doubleday.

Capra, F. and Luisi, P. L. (2014). The Systems View of Life. Cambridge: Cambridge University Press ebook.

Cassirer, E. (1992). An Essay on Man. New Haven: Yale University Press.

Castells, M. (2009). Communication Power. New York: Oxford University Press ebook.

Dellsén, F. (2020). Explanatory Consolidation: From 'Best' to 'Good Enough'. [Preprint] http:/ /philsciarchive.pitt.edu/id / eprint/17290 (accessed 2020-06-20).

Dickson, B. (2018). Law in Northern Ireland. 3rd Edition. London: Hart Publishing. 
Douzinas, C. And Nead, L. (1999). Eds. Law and the Image: The Authority of Art and the Aesthetics of Law. Chicago: Chicago University Press.

Douzinas, C. and Perrin, C. (2011). Critical Legal Theory. London: Routledge.

Du Sautoy, M. (2019). The Creativity Code: Art and Innovation in the Age of AI. Cambridge, Mass: Harvard University Press.

Dworkin, R. (1981). Taking Rights Seriously. London: Duckworth.

Dworkin, R. (1987). Law's Empire. Cambridge MA: Harvard University Press.

Feenan, D. (2009). Forward: Socio-legal studies and the humanities. International Journal of Law in Context 5,3: 235-242. https: / / doi.org/10.1017/S1744552309990097.

Finnis, J. (2011). Natural Law and Natural Rights. 2nd Ed. Oxford: Oxford University Press.

Fokt, S. (2014). The Cluster Account of Art: A Historical Dilemma. Contemporary Aesthetics vol.12:

“Frith, C. (2007). Making Up the Mind: How the Brain Creates Our Mental World. Oxford: Blackwell.

Gaut, B. (2000). "Art" as a Cluster Concept. In Carroll, N. ed. Theories of Art Today. Madison: University of Wisconsin Press: pp. 25-44.

Gaut, B. (2005). The Cluster Account of Art Defended. British Journal of Aesthetics vol. 45: 273-88.

Goodenough, O. (2001). Cultural Replication Theory and Law. The Gruter Institute Working Papers on Law, Economics, and Evolutionary Biology vol.1 (1), Article 3: 1-15.

Hart, H.L.A. (1961). The Concept of Law. Clarendon: Oxford University Press.

Imdahl, M. (1996). Gesammelte Schriften. 3 Bde. Frankfurt: Suhrkamp.

Kandel, E.R. (2016). Reductionism in Art and Brain Science. New York: Columbia University Press eBook.1-15.

Kövecses, Z. (2002). Metaphor: A Practical Introduction. Oxford: Oxford University Press.

Kuhn, T. (1962). The Structure of Scientific Revolutions. Chicago: University of Chicago Press ebook.

Lanza, R. and Berman, B. (2009). Biocentrism. Texas: BenBella Books eBook.

Lanza, R. and Berman, B. (2016). Beyond Biocentrism. BenBella Books eBook.

Lanza, R. and Pavšič, M., with Berman, B. (2020). The Grand Biocentric Design: How Life Creates Reality. Texas: BenBella Books eBook

Leiter, B. (2007). Naturalizing Jurisprudence: Essays on American Legal Realism and Naturalism in Legal Philosophy. Oxford: Oxford University Press.

Lent, J. (2017). The Pattering Instinct: a cultural history of humanity's search for meaning. Amherst, NY: Prometheus Books eBook.

Levit, N., Verchick, R. and Minnow, M. (2016). Ed's. Feminist Legal Theory: A Primer. 2nd Ed. New York: New York University Press.

Levitin, D.J. (2006). This is your Brain on Music: The Science of a Human Obsession. New York: Plume/ Penguin. 
Lotz, C. (2015). The Art of Gerhard Richter: Hermeneutics, Images, Meaning. London: Bloomsbury Academic eBook.

Madison, S. (2019). Critical Ethnography: Method, Ethics, and Performance. California: SAGE Publications.

Magee, B. (2002). The Tristan Chord: Wagner and Philosophy. New York: Holt Paperbacks.

Manderson, D. (2000). Songs without music: aesthetic dimensions of law and justice. Berkeley: University of California Press.

Manderson, D. (2012). Kangaroo Courts and the Rule of Law: The Legacy of Modernism. Italy: Routledge ebook.

Manderson, D. (2018). Law and the Visual: Representations, Technologies, Critique. United Kingdom: University of Toronto Press, Scholarly Publishing Division ebook.

Marcum, J.A. (2015). Thomas Kuehn's Revolutions. London: Bloomsbury Academic ebook.

Meskin, A. (2007). The Cluster Account of Art Reconsidered. British Journal of Aesthetics vol. 47: 388-400.

Paterson, D. (2019). The Poem: Lyric, Sign, Metre. London: Faber and Faber eBook.

Posner, R.A. (1990). The Problems of Jurisprudence. Cambridge, MA: Harvard University Press.

Posner, R.A. (1996). Law and Legal Theory in the UK and USA. United States: Clarendon Press.

Posner, R.A. (2014). Economic Analysis of Law. 9th Ed. New York: Walter Klewer Law \& Business.

Psillos, S. (2016). The Realist Turn in the Philosophy of Science. [Preprint] http: / / philsci-archive.pitt.edu / id/eprint/ 12440 (accessed 2020-06-20).

Putnam, H. (1990). Realism with a Human Face. Constant, J. Ed. Cambridge, MA: Harvard University Press.

Quine, W.V. (1990). Pursuit of Truth. Cambridge, MA: Harvard University Press.

Raz, J. (1980). The Concept of a Legal System: An Introduction to the Theory of Legal System. 2nd Ed. Clarendon: Oxford University Press.

Ross, A. 'Secret Passage', New Yorker, 25 April 2011. Online. Available http://www.newyorker.com/ arts / critics / atlarge/2011/04/25/110425crat_atlarge_ross (accessed May 4 2020), 85.

Ross, A. 2020. Wagnerism: Art and Politics in the Shadow of Music. New YorK: Farrar, Straus and Giroux ebook.

Sarat, A., Anderson, M. and Frank, C.O. Eds. (2009). Law and the Humanities: An Introduction. Cambridge: Cambridge University Press.

Sarat, A. (2011). Ed. Imagining Legality: Where Law Meets Popular Culture. Tuscaloosa: University of Alabama Press.

Schauer, F. (2012). On the Nature of the Nature of Law. Archiv für Rechst- und Sozialphilosophie vol. 98 (4): $457-467$.

Schauer, F. (2013). On the Open Texture of Law. Grazer Philosophische Studien 87,1: 197-215. https:// doi.org/10.1163/9789401210119_013. Open copy at http:/ / ssrn.com/abstract=1926855. 
Schauer, F. (2015). The Force of Law. Cambridge: Harvard University Press.

Schauer, F. (2017). Law's Boundaries. Harvard Law Review vol.130: 2434-2462.

Tamanaha, B. Z., Hawkins, K. (1997). Realistic Socio-legal Theory: Pragmatism and a Social Theory of Law. United Kingdom: Clarendon Press.

Tamanaha, B. Z. (2001). A General Jurisprudence of Law and Society. Oxford: Oxford University Press.

Tamanaha, B. Z. (2006). Law as a Means to an End: Threat to the Rule of Law. United States: Cambridge University Press.

Tamanaha, B. Z. (2009). Beyond the Formalist-Realist Divide: The Role of Politics in Judging. Ukraine: Princeton University Press.

Tamanaha, B. Z. (2012). What is "General Jurisprudence"? A Critique of Universalistic claims of Philosophical Concepts of Law. Transnational Legal Theory 2: 287-308.

Tamanaha, B. Z. (2014). Legal Realism in Context. Washington University Legal Studies Research Paper Series No. 14-12-01.

Tamanaha, B. Z. (2015). What is Law? Washington University Legal Studies Research Paper Series No. 15-01-01.

Tamanaha, B. Z. (2016). Necessary and Universal Truths about Law. Washington University Legal Studies Research Paper Series No. 16-06-02.

Tamanaha, B. Z. (2017). A Realistic Theory of Law. Cambridge: Cambridge University Press ebook.

Tamanaha, B. Z. (2018). Law's Evolving Emergent Phenomena: from Rules of Social Intercourse to Rule of Law Society. Washington University Legal Studies Research Paper Series No. 18-03-03.

Tamanaha, B. Z. (2019). 'Sociological Jurisprudence Past and Present', Washington University Legal Studies Research Paper Series, No. 19-03-01.

Unger, R. (1996). What Should Legal Analysis Become? London: Verso.

Unger, R. (2015). The Critical Legal Studies Movement: Another Time, A Greater Task. London: Verso.

Villa, V. (1997). Legal Theory and Value Judgments. Law and Philosophy 16, 447-477. https://doi.org/ $\underline{10.1023 / \mathrm{A}: 1005821004473}$

Zeki, S. (2001). Artistic Creativity and the Brain. Science vol.293. 5527:51-52 http:/ / www.sciencemag.org/ cgi/ content/ full/293/5527/51

Zeki, S. (1993). A Vision of the Brain. Oxford: Blackwell Scientific.

Zeki, S. and Goodenough, O. (2006). Law and the Brain. Oxford: Oxford University Press.

Zeki, S. (2009). Splendour and Miseries of the Brain: Love, Creativity, and the Quest for Human Happiness. Chichester: Wiley-Blackwell eBook. 


\section{Appendix A: Theft in NI}

\section{(1) Historical heuristic:}

The Northern Ireland Legal System (N.I.), is one of three differentiable legal jurisdictions within the political structure of the 'United Kingdom of Great Britain and Northern Ireland'. They are 1) 'England and the Principality of Wales'; 2) 'Scotland' and 3) 'Northern Ireland' and correspond to the remnant of the unified sovereign political and geographical territories of England, Scotland and Ireland. With the secession of the twenty six Irish counties to declare the independent state of 'The Republic of Ireland' founded as the 'Irish Free State' in 1922, the six counties of Ireland remaining within the U.K. were reconstructed by statute of Westminster in 1920 as the new state of 'Northern Ireland'. It has a distinctive heritage of elements of ancient customary Irish Brehon law and Norman French law following the 1169 invasion. English Common Law was introduced gradually from1300 and in the 1607 inheritance Case of Tanistry, Brehon law was declared incompatible and unenforceable.

Of the three legal jurisdictions within the U.K., N.I. most resembles that of England, as after the 17th century the two legal jurisdictions developed contiguously. English law too has early French influences, dating from the 11th century Norman conquest. The Brehon component in N.I. law is a point of criteriological differentiation, but has limited residual legacy, restricted to minor doctrinal aspects of property and estates regulation. Scotland is anomalous within the trilogy, as it retains much of the European Roman 'Civil Law' through it's historic Jacobite associations augmented by the English Common Law. Most significantly, the adversarial court system and Stare Decisis doctrine of judicial precedent. Unlike Scotland or England and Wales, laws in N.I. are rooted in a written constitution, The Government of Ireland Act 1920, coming into force and creating the new state of N.I. on 3 May 1921.

Unlike under the U.S. Constitution, N.I. has no claim to independent sovereignty, but is a constitutional state within the sovereign authority of the U.K. Initially N.I was directly ruled from Westminster, but subsequently with increasing authority and power delegated to the local Parliament, now Assembly. Westminster remains supremely sovereign and can repeal the N.I. Act and reassume all delegated authority at will. The Belfast (Good Friday) Agreement 1998 was approved by the people of N.I .as a political settlement of the 40 years of civil unrest known locally as 'The Troubles'. Together with the 1920 Act, these two pieces of legislation form the structure of the N.I. legal system. While in theory both are at the sufferance of the sovereign will of Westminster, it is highly unlikely that the 1998 Agreement could be over turned as a matter of political pragmatism.

Post BrExit on January 31 2020, with the secession by the U.K. from the E.U., N.I. is no longer subject to the supra legal system of Brussels, so what would have been a key indexing criteria of the N.I. legal system is no longer a factor. The U.K. is a constitutional monarchy, in which sovereign power is held and exercised by the Parliament of Westminster. Not by 'the people', as in the U.S. Republic. The largely unwritten U.K. Constitution, is not in a single document, but comprises various written texts along with unwritten long standing 
'conventions' and 'customs'. It has three core principles, which were broadly adopted by the U.S.: 1) 'The Principle of the Rule of Law'; 2) 'The Principle of Parliamentary Sovereignty' and 3) 'Principle of the Separation of Powers'. As in the U.S. and MA, power is shared between the 'Executive' Civil Service, the 'Legislature' of Parliament (lower House of Commons, upper House of Lords) and the 'Judiciary', but with important differences. The Prime Minister sits in the Parliamentary House of Commons, not the Executive and the Judiciary are apolitical, selected for ability and bipartisanship by an independent 'Judicial Appointments Commission'. The U.K. Civil Service in N.I. is called the 'N.I. Office (NIO)' and in Westminster, N.I. affairs are overseen by the 'N..I Affairs Committee'. The 'N.I. Assembly', set up by the Westminster (NI). $\underline{\text { Act 1998, }}$, under the Good Friday Agreement, has it's own local executive.

Having originated the Common Law system, to be adopted by the U.S., U.K. and N.I. laws originate by legislation or through court decisions. N.I. legislation is either on 'transferred' or 'reserved' matters. Reserved matters are legislated for N.I. directly by Acts of Parliament and transferred matters are legislated on by the local N.I. Assembly. Additionally, N.I. is subject to secondary legislation made under primary U.K. law, in the form of 'Orders in Council' as 'Statutory Rules' or 'Instruments'. The Government of Ireland Act 1920 set up the 'Supreme Court of Judicature of N.I.' to which all legal practitioners swear allegiance and are officers. Appeals are heard first by The 'Court of Appeal of N.I.' then on final appeal to 'The U.K. Supreme Court'. Unlike SCOTUS, this Court is not limited to constitutional matters, but all cases as a court of final jurisdiction. In N.I. the Lord Chief Justice and Lord Justices of Appeal are appointed by the Crown.

As in MA, N.I. has a system of local councils, recently reduced to eleven by the Local Government Act (NI) 2014.

Like the jurisdiction of England and Wales, the legal system of N.I. is best described as a formalistic legal system, in which legal validity is ultimately a matter of correct structural form, not of substantive content, as in the U.S.

\section{(2) Primary Indexing Criteria}

Text

- The U.K. Constitution is a predominantly unwritten system of coherent, but contingent, written texts, textual artefacts and customary conventions.

- The N.I. Constitution is a written text and artefact structured as an Act of Parliament.

- Written legislative texts and artefacts in N.I. on 'transferred' or 'reserved' matters, both primary and secondary, have legal priority over judicial precedent, customs, conventions and international Treaties due to the absolute sovereignty of Parliament.

- Judicial decisions follow the Doctrine of Stare Decisis, provided they are decisions of duly constituted Courts and published (as physical or digital artefacts) in the authorised system of Law Reports.

\section{Power}


- Absolute legal power lies with H.M. The Queen sitting in her Parliament, as Constitutionally constituted.

- All power in the state is exercised in accordance with the Principle of the Rule of Law and all are equal under the law.

- Power is distributed according to the Principle of the Separation of Powers, delegated to the N.I .Assembly on 'transferred' matters, subject to scrutiny and prorogation at the will of Parliament.

- $\quad$ Power is also exercised by the Courts through precedent, under the Constitution and subject to the will of Parliament.

- On 'transferred' matters, power exercised by the N.I. Assembly can be transferred or reserved to the eleven local Councils in N.I.

\section{(3) Secondary Indexing Criteria}

\section{Painting and Digital imaging}

- Materials, manner, media and content reflect the power, authority and cultural history of the law. Although digital photography is increasingly a preferred medium, legal imagery has been historically in the 'Grand Manner' of formal portraiture, often a dark palette of oil, large canvases enveloped in in heavy gilt frames. Judicial and advocate group portraits are common and senior office holders are often memorialised in full formal attire, in systematic, historical order, staged in the grandest of Halls, to emphasis the continuity of power, privilege and authority.

\section{Plastic Arts}

- From the construction of Court and Legislative furniture to the metaphorical sculpture is of the Roman goddess 'Iustitia' holding the 'scales of Justice' adorning the Old Bailey Court in London. A legacy of a far more ancient Middle Eastern iconography, again symbolises the impartial Principle of the Rule of Law and the power of adjudication and punishment. The Royal Crown, Orb and Sceptre, the 'Woolsack', the Staff of 'Black Rod', the wooden Gavels of Speaker of the House and Judiciary, Union Jack Flag of the U.K. and the enumerable military, ecclesiastical, chivalric and Greco-Roman statues and artefacts that adorn the legal structures of the U.K. and N.I., all reinforce power and authority.

\section{Dress Design}

- $\quad$ The wearing of 17th century period powder wigs and gowns, an historical sign of social status, wealth and power, persists for both Court advocates and the judiciary. The Monarch, Speaker of the House of Commons and Black Rod illustrate the significant use of period dress to further enhance authority and power. Designs reference the sociocultural monarchical and imperial history of the U.K., along with it's Medieval chivalric and Protestant Christian heritage. Uniforms and badges distinguish official law enforcement officials, from police officers to traffic and prison wardens. 


\section{Architecture}

- Use of acoustically and spatially distinct period structures, such as the Palace of Westminster, convey power, authority and continuance. Similarly, the persistent use of the 'Grand', Gothic, Romanesque, neo Classical and Ecclesiastical architectural designs and motifs historically and for newer structures (such as Buckingham Palace, the Belfast Courts and NI Assembly in Stormont House) references the generally understood tropes of the magisterium and power of the Christian Church, Republican and Imperial Rome. The grandeur of the buildings is essential to their functionality.

\section{Rhetoric}

- As the advocacy of persuasion and negotiation, it is dominantly accusatory, persuasive and adversarial within the Courts and mediational, negotiational and arbitrational in the Civil Tribunal systems.

\section{Dramatic enactment}

- The literary representation of legal drama, as a chronological sequence of events for effecting the exercise of power and social control, is reflected in the artefacts of arrest warrants, document discovery, petitions, pleadings, Writs, rules of evidence, formal judgments. Law is an extended narrative about a text dramatically unfolding in the presence of an 'audience'. The audience is the system of role players (e.g. judge, court official, lawyer, police and prison officer, victim, accused, defendant, plaintiff, witnesse, juror) and includes anyone experiencing the dramatic enactment. The stage equally varies from the City street to the ritualistically regulated court room, legislature, law library, web site, indeed any place where the enactment unfolds or is engaged.

Style

- The dominant style of N.I. legal works is a pluralist, relativistic formalism that constructs a legal reality. Yet, 'style' does not dictate the work: The works collectively determine the dominant style. Laws crafted formalistically, facilitate the necessary informational complexity, needed for regulating a complex society, In turn, this prioritises technique and method, with a correlative downside of constraining legal experimentation and innovation. N.I. laws and the legal system they collectively construct, are structurally conservative, conventional, but non-absolutist and therefore substantively pluralist. A legal work is valid if the formal criteria for creation are satisfied. Substantive content is irrelevant to validity, but remains critical for effectiveness.

\section{Communication - system - network}

- The predominance of written texts, over oral, allows the communication of the complex and numerable laws needed to regulate the highly complex society of 21 st century N.I. 
as part of the U.K., competing in a global economy. The LCATH ontologically prioritises the individual legal work, so N.I. laws integrate systemically (a descriptive relation of coherence) through the shared synthetic brain structure through our human pattern instinct, that identifies and integrates the real legal works of common provenance in structure, heuristic and style.

- Courts are structured hierarchically within districts and jurisdictions. Unified law enforcement throughout N.I. Is by the Police Service of Northern Ireland (PSNI) and criminal prosecution by the Office of the Director of Public Prosecutions (DPP).

- $\quad$ Case and legislative reporting in N.I. and U.K., is systematically organised through textual artefacts and digital records.

\title{
(4) The Synthetic Brain Structure of the law of Theft in NI
}

\author{
Meta Structure: \\ - $\quad$ Digital Artefact: www.legislation.gov.uk \\ - $\quad$ Citation: The Theft Act (Northern Ireland) 1969 (c.16)
}

\section{Basic Textual Defn:}

- "Sec.1 Basic definition of theft. (1)A person is guilty of theft if he dishonestly appropriates property belonging to another with the intention of permanently depriving the other of it; and "thief" and "steal" shall be construed accordingly.(2)It is immaterial whether the appropriation is made with a view to gain, or is made for the thief's own benefit."

\section{Systemic Structure of the Offence:}

- Similar to the MGL Code, the Theft Act acknowledges the complexity of the act of dishonest taking of another's property by creating separate offences under the Act. These are mostly individuated by the manner of the 'taking' of the property. Not it's value, type or the character of the victim as in the MGL. Robbery (Sec.8), Burglary (Sec.9), and Aggravated Burglary (Sec.10) followed by specific offences differentiated by property type (Sec.11-14). Fraud and Blackmail are proscribed (Sec.15-20), handling stolen goods (Sec.21-23A) and possessing housebreaking tools (Sec.24).

- Unlike the MA law, in which the misdemeanour or felony charge is determined by the value of the property taken and the stated punishment level set accordingly, the N.I. Act details punishment ranges for the offences and leaves it to the presiding Court to determine the form and degree of punishment that is proportionate to the seriousness of the offence. The MGL is a formal unified systemised Code, a distinct compound legal work consisting of a variable set of integrated, coherent distinct sub works on differing matters. The N.I. Act, is a unified single legislative work. To modify the MGL you 
change, delete text or add 'works' (Titles) without repealing the entire Code. To modify an Act, you can repeal or amend parts by subsequent Acts or by subordinate legislation. But should the majority of the Theft Act (Northern Ireland) 1969 require amendment, the U.K. Parliament would have to repeal the entire Act and enact another legislative work in substitution. Given the the 1969 Act was enacted by the now defunct N.I. Parliament, amendments and repeal of that particular legislation would have to be by Westminster not the devolved local Assembly, especially as the Act was designed to bring the law of theft in N.I. into line with that of England and Wale, passed in 1968.

\section{Heuristic:}

- $\quad$ There is no equivalent in N.I. of the Constitutional right to hold property in MA and the U.S. generally. The recognition of property rights was first formalised in the Roman Institutes of Justinian in $533 \mathrm{CE}$ and is now recognised globally. The influence of Roman law in the UK eventually influenced the English Common Law of larceny, which is the common ancestor of both the MGL S.30 and Theft Act. Since there is no inviolable, constitutionally enforceable right to property in N.I., given the non-substantive formalism of the legal works, the Act could be repealed by a sovereign U.K. Parliament at will.

\section{Appendix B: Larceny in MA}

\section{(1) Historical Heuristic:}

The history of Massachusetts is the history of the United States. The Legal system of the Commonwealth of Massachusetts (MA) is one of the fifty legal systems of the sovereign constitutional states to have ratified the Constitution of the United States of America (1789) and delegated power to it's governmental institutions.

Human Paleoindians first settled in Turners Hill Falls MA c.12,000 BCE and European presence is recognised from the 17th century CE arrival of Englishman Bartholomew Gosnold in 1602. Despite a French presence of de Champlain in 1605, the arrival of the Mayflower Pilgrims on November 9, 1620, signing the 'Mayflower Compact' on November 11, marked the imperial ambitions of the U.K. and adoption of English law in the region. Charles I granted the 'Province of Massachusetts Bay' a Charter in 1629 but this was revoked in 1684 and shortly after, Sir Edmund Andros was despatched to Boston from England to take full control of the 'Dominion of New England' which in turn was swiftly overthrown in the Boston Revolt of 1689. Two 18th century acts of British provocation, the Royal Proclamation of 1763, ordering a cessation of western colonial explanation in the Americas and the Coercive Acts 1774 led to the rebellion of 
the War of Independence starting with the Battle of Lexington in 1775. The Constitution of the Commonwealth of Massachusetts was ratified in 1780, the last of the original states to do so and the Preamble and Governmental structure was adopted by the framers of the 1789 Constitution.

In terms of legal provenance, as there was suddenly a vacuum of effective legal regulation, the early settled Province of Massachusetts Bay and subsequent Commonwealth, largely re-enacted the prorogued English laws in order for the new society to function. The accretion of distinctive MA laws occurred from statehood, but there followed further period of full-scale adoption of English laws in the late 19th century, in order to regulate the fast emerging Industrial Revolution, notably intellectual property, contract and corporatism. The legal provenance of MA has, since Western colonisation, been steeped in the legal culture of the English system. The MA and U.S. Constitutions each substantively incorporate the Lockean 'Divine Natural Rights' theory of the English Bill of Rights of 1689, the three 'Principles of the Separation of Powers', with a significant additional influence of the contemporary French Declaration of the Rights of Man and of the Citizen 1789. Unlike many other U.S. states, there is no other residual influence of French, Dutch or Hispanic legal culture in MA. In provenance, it is the most English legal culture in the US, although all states have adopted the English concept of the Rule of Law, adversarial court procedure and Common Law with a version of the Doctrine of Precedent or Stare Decisis. Despite ratifying the U.S. Constitution, it is the MA Constitution of 1780 that is is the sovereign source of law in MA, unlike the N.I. Constitution, which is a grant 'at will' of power from a sovereign U.K. Parliament. It remains moot whether the MA delegation of sovereignty to the Federal Government could actually be revoked without the spectre of a treasonous secession, as occurred during the Civil War.

The MA Constitution bequeathed to the U.S. the then, radical idea of a government 'of and by the people', although 'the people' as a class, were then white, male, Christian and capitalist. It is a tripartite structure designed to reformulate the English separation of powers in the mode of the early Roman Republic, as reported by the historian Polybius, well known to the framers. The framers were also familiar with the principle as formulated in a major French treatise by Montesquieu, De 'esprit des lois (1748). Both state and Federal civic regulation and lawmaking is by way of a distinct 'Executive' and 'Legislature' adjudicated by a 'Judicial' branch. The Governor (MA) and President (U.S.) are head of the Executive, originating and vetoing legislation, preparing budgets, granting pardons, nominating Judges and are Commander of Chief of the National Guard (MA) and U.S. Armed Forces (POTUS). Both legislatures, the Massachusetts General Court and Congress comprise a lower 'House of Representatives' and an upper 'Senate'. In MA state judicial disputes are under the 'Massachusetts Supreme Court' and Federal cases heard under the 'US District Court for the District of Massachusetts', appealed to the 'U.S. Court of Appeals for the 1st Circuit.' Unlike in N.I. and the U.K., where the separation of Executive, Legislative and Judicial appointment and power is almost complete, in MA and the U.S. the process is less clearly differentiated, particularly with respect to the dominance of the Executive in Judicial appointment, including the Supreme Courts of both. Also, the notable absence at Federal level, less so at state, of a permanent Civil Service truly independent of executive influence.

Originally, the Commonwealth had a bottom up civic structure, but power and control has been increasingly centralised within the State Government. Of MA's 50 cities, 301 towns in 14 Counties, almost all of the executive Councils have been abolished since 1997. Only the incorporated regional ‘New England Towns' operate as local government structures. 
Overall, the legal systems of both MA and the U.S. can be described as 'substantively instrumentalist' or 'pragmatic' legal systems, in which legal validity is ultimately a matter of substantive content, not of structural form, as is the case in N.I. and the U.K.

\section{(2) Primary Indexing Criteria}

\section{Text}

- The MA and U.S. Constitutions are both written texts and artefacts, around which unwritten customs and conventions have accumulated.

- Written legislative texts and artefacts in MA are either State or Federal. Federal have priority on 'transferred' matters, and both have general legal priority over judicial precedent, customs, conventions and international treaties. The exception to legislative and precedent priority is in constitutional matters reserved for adjudication by the SCOTUS under the U.S. Constitution, which MA ratified on accession.

- Judicial decisions follow the Doctrine of Stare Decisis, provided they are precedents of duly constituted Courts and published (as physical or digital artefacts) in the authorised system of Law Reports.

\section{Power}

- Absolute power in MA is that of the U.S. Constitution on matters transferred on ratification, the State exercising residual power in respect of all reserved matters.

- All power is exercised in accordance with the Principle of the Rule of Law and all are equal under the law.

- Power is distributed according to the Principle of the Separation of Powers, between the State and Federal Government.

- $\quad$ Power is also exercised by the Courts through precedent, under both the State and US Constitutions.

- $\quad$ On 'reserved matters', power in MA can be transferred or reserved to the Cities and Towns.

\section{(3) Secondary Indexing Criteria}

\section{Painting and Digital Imaging}

- Materials, manner, media and content reflect the power, authority and cultural history of the law. Although digital photography is increasingly a preferred medium, legal imagery has been historically in the 'Grand Manner' of formal portraiture, often a dark palette of oil, large canvases enveloped in in heavy gilt frames. Judicial and advocate group portraits are common and senior office holders are often memorialised in full formal attire, in systematic, historical order, staged in the grandest of Halls, to emphasis the continuity of power, privilege and authority. 


\section{Plastic Arts}

- From the construction of Court and Legislative furniture to the metaphorical sculpture is of the Roman goddess 'Iustitia' holding the 'scales of Justice', adorning a multitude of legal buildings. A legacy of a far more ancient Middle Eastern iconography, again symbolises the impartial Principle of the Rule of Law and the power of adjudication and punishment. The prominence of the individual actor within MA and U.S. legal culture, has resulted in enumerable representational sculptures, such as that of 19th century Attorney Rufus Choate in the John Adams Courthouse. John Adams, John Singleton Copley, Paul Revere and Benjamin Franklin are all honoured with effigies in public spaces in historic Boston. The State Seal and flag, wooden Gavels of Speaker of the Houses of the General Court, Judges, and the enumerable military, ecclesiastical, GrecoRoman statues and artefacts that adorn the legal structures of MA, reinforce State power and authority.

\section{Dress Design}

- $\quad$ Reflects a turn away from 18th century British imperial rule toward, a less ostentatious couture. Ecclesiastically Calvinist and bereft of monarchical and medieval chivalric influences, the general demeanour in MA is one of 'Boston Casual'. Judges wear simple black gowns, even senior judiciary have modest formal regalia, and no powdered wigs are worn. Uniforms and badges distinguish official law enforcement officials, from police officers to traffic and prison wardens. The flag of the U.S. Republic is a common badge and motif.

\section{Architecture}

- Varies from the historic 18th century Old State House and Federal building of the Massachusetts State House and the John Adams Courthouse, to the concrete urban renewal of the Boston City Hall in the 1960s. The legal buildings reflect the early settlement of the Bay Area and its history and growing economic prosperity, from foundation to present.

\section{Rhetoric}

- As the advocacy of persuasion and negotiation, it is dominantly accusatory, persuasive and adversarial within the Courts and mediational, negotiational and arbitrational in the Civil Tribunal systems.

\section{Dramatic Enactment}

- The literary representation of legal drama, as a chronological sequence of events for effecting the exercise of power and social control, is reflected in the artefacts of arrest 
warrants, document discovery, petitions, pleadings, Writs, rules of evidence, formal judgments. Law is an extended narrative about text(s) dramatically unfolding in the presence of an 'audience'. The audience is the system of role players (e.g. judge, court official, lawyer, police and prison officer, victim, accused, defendant, plaintiff, witnesse, juror) and includes anyone experiencing the dramatic enactment. The stage equally varies from the City street to the ritualistically regulated court room, legislature, law library, web site, indeed any place where the enactment unfolds or is engaged.

\section{Style}

- The dominant style of MA legal works, as across the U.S. generally, is traditional with transcendent (absolutist) aspects. Organised within a pluralist, relativistic formalism that constructs a legal reality. It seeks to advance the priority and unitary truth of the substantive, faith based divinely granted natural human rights in both the MA and U.S. Constitutions. Form gives way to substantive rights, adjudicated upon by SCOTUS as final arbiter. The MA and U.S. legal style is best described as 'substantive intrumentalism', or 'pragmatism', the instrumentalist aspect being achieved though the use of formalism to advance the substantive principles.

- Unlike in N.I. where a legal work can be valid independent of substance, if the formal criteria are satisfied, in MA laws formally enacted are presumed valid unless substantively negated. Style does not dictate the work: The works collectively determine the dominant style. Laws crafted traditionally and transcendently using formalistically criteria, facilitate to a significant degree the necessary informational complexity needed for regulating a complex society. In turn, this prioritises content over technique and method, with a correlative upside of the possibility for legal experimentation and innovation within the unitary truth of the MA and U.S. Constitutions. MA laws and the legal system they collectively construct, are structurally traditional, transcendental and substantively absolutist and monist, with conservative, conventional formalist aspects.

\section{Communication - system - network}

- The predominance of written texts, over oral, allows the communication of the complex and numerable laws needed to regulate the highly complex society of 21st century MA as part of the Federal U.S., competing in a global economy. The LCATH ontologically prioritises the individual legal work, so MA and Federal laws integrate systemically (a descriptive relation of coherence) through the shared synthetic brain concept via our human pattern instinct, that identifies and integrates the real legal works of common provenance in structure, heuristic and style.

- Courts are structured hierarchically within districts and jurisdictions. Unified law enforcement throughout MA is by the local City and Town police forces and the State Troopers. Criminal prosecution is by the local District Attorneys.

- State and Federal case and legislative reporting is systematically organised through textual artefacts and digital records. 


\section{(4) The Synthetic Brain Concept of the law of larceny in MA:}

\section{Meta Structure:}

- Digital Artefact: www.malegislature.gov

- $\quad$ Citation: MGL Part IV Title 1 ch. 266 S 30

\section{Basic Textual Defn:}

- S. 30 (1) "Whoever steals, or with intent to defraud obtains by a false pretence, or whoever unlawfully, and with intent to steal or embezzle, converts or secretes with intent to convert, the property of another as defined in this section, whether such property is or is not in his possession at the time of such conversion or secreting shall be guilty of larceny..."

\section{Systemic Structure of the Offence:}

- As reflects the Codified form of the General Laws, the crime and punishment of theft is individuated into distinct offences according to three variables: 1) the monetary 'value' of the property; 2) the 'type' or kind of property and 3) the 'character' of the victim, for example if one is elderly. This results in a preliminary separation of offences into the lessor 'misdemeanour' of larceny (property value up to $\$ 1200$.) and the more serious 'felony' charge (value over \$1200.) punishment increase accordingly. Further offences are differentiated using the variables, such as

1. Obtaining computer services by fraud (S.33A)

2. Fraudulent use of credit cards (S.37C)

3. Larceny of bicycles (S.41)

4. Fraud or embezzlement by city, town or county officers (S.51) and

5. Buying or receiving stolen goods (S.60)

\section{Heuristic:}

- The inalienable right to hold property is a substantive right in the State Constitution affirmed in the subsequent U.S. Constitutional artefact, so not subject to foreseeable Constitutional challenge.

- "Part the First Article I. All men are born free and equal and have certain natural, essential, and unalienable rights; among which may be reckoned the right of enjoying and defending their lives and liberties; that of acquiring, possessing, and protecting property; in fine, that of seeking and obtaining their safety and happiness." (Constitution of Massachusetts 1780)

- All Larceny laws in the U.S. have their roots in the colonial English Common Law, pursuant to which larceny involves the 'trespassory taking' (caption) and 'carrying 
away' (asportation, removal) of the 'tangible personal property of another with the intent to permanently deprive the owner of its possession'. Larceny is now codified as a statutory crime in all U.S. jurisdictions, but has no direct equivalent in modern U.K. law.

- $\quad$ S.30 was debated, passed by both Houses of the General Court and ratified into force by the then Governor of MA as per originating procedure. 